\title{
Traditional high-rise unreinforced masonry buildings: modeling and influence of floor system stiffening on their overall seismic response
}

\author{
Juan Jiménez-Pacheco \\ Director of Red Sísmica del Austro, University of Cuenca, Cuenca, Ecuador \\ juan.jimenez@ucuenca.edu.ec (corresponding author) \\ Ramón González-Drigo \\ Professor, Department of Structural Engineering, UPC, Barcelona, Spain \\ jose.ramon.gonzalez@upc.edu
}

Lluis G. Pujades Beneit

Professor, Department of Civil and Environmental Engineering, UPC, Barcelona, Spain

lluis.pujades@upc.edu

Alex H. Barbat

Professor, Department of Civil and Environmental Engineering, UPC, Barcelona, Spain alex.barbat@upc.edu

José Calderón-Brito

Researcher, Red Sísmica del Austro, University of Cuenca, Cuenca, Ecuador

jose.calderon@ucuenca.edu.ec

\begin{abstract}
This paper summarizes a study whose primary objectives were to develop a model for nonlinear static analysis of unreinforced masonry (URM) buildings, considering the flexibility of the floor system and analyzing the influence of stiffening the floor system on the overall seismic response of such buildings. With this aim, a six-story building typical of the Eixample-Barcelona district was used as a case study. All the macro-elements, those that constitute the walls and the floor system, were developed with one-dimensional spring elements. The influence of stiffening the floor system was analyzed by applying conventional stiffening interventions to the two floor systems common in the Eixample-Barcelona district.
\end{abstract}


The overall seismic response was evaluated in terms of modal parameters, the characteristics of the pushover curves and the deformed shape of the floors. The outcomes are discussed in relation to recent studies and explained in the context of previous studies. Finally, in the two unstiffened cases of the prototype building, the stiffening of the floor system slightly increases in fundamental periods, slightly to moderately increases in base shear capacities, and significantly decreases in displacement capacities.

Keywords: traditional URM buildings; flexible floor; spring-type macro-elements; pushover analysis; stiffening of floors

\section{INTRODUCTION}

The problem of seismic assessment and retrofitting of unreinforced masonry (URM) buildings has become one of the main topics of interest in structural engineering due to the relative decrease in new construction compared to interventions on existing buildings (Magenes and Penna 2011). The topic itself is very complex due to the significant variability in architectural typologies and materials in URM buildings and the factors that influence their seismic behavior. One common, determining factor in old URM buildings is the in-plane flexibility/stiffness of the floor system.

In general, seismic standards for buildings classify floor diaphragms using the ratio of the inplane stiffness of the floor diaphragm to that of the lateral load resisting system, expressed in terms of deformations. The most widespread criterion (FEMA 273 1997; FEMA 356 2000; ASCE/SEI 7-10 2010; ASCE/SEI 41-13 2014; BHRC 2015; NZSEE 2017; ASCE/SEI 41-17 2017) classifies floor diaphragms into three categories: flexible, rigid or stiff, depending on the ratio of the maximum horizontal deformation along its length under a uniformly distributed lateral load $\left(\Delta_{\mathrm{D}}\right)$ to the average lateral displacement of the lateral load resisting system (e.g. shear walls in the case of URM buildings) of the story immediately below the 
diaphragm or average story drift $\left(\Delta_{\mathrm{W}}\right)$. Diaphragms are considered flexible if $\Delta_{\mathrm{D}} / \Delta_{\mathrm{W}}$ is equal to or greater than 2.0, and rigid if $\Delta_{\mathrm{D}} / \Delta_{\mathrm{W}}$ is equal to or less than 0.5 . For $\Delta_{\mathrm{D}} / \Delta_{\mathrm{W}}$ values within the range of 0.5 and 2.0, the diaphragm is classified as stiff. Although the categories are accompanied by descriptions of behavior, these are very general and unreliable (TenaColunga 2015; Nakamura et al. 2017b; Srisangeerthanan 2018). Recently, Nakamura et al. (2017b) and Eivani et al. (2018) proposed more refined and useful classifications based on the dominant characteristics of diaphragm deformation and on how incremental flexibility of the diaphragm affects wall responses. From parametric studies, in which the fundamental period of the diaphragm constitutes the basic parameter of classification, four categories of diaphragm are established. In Nakamura et al. (2017b) the bending deformation component is as important as the shear component, which is clearly dominant in one of the ranges. Conversely, Eivani et al. (2018) found remarkably greater shear deformation sensitivity in the diaphragms to the asymmetry and flexibility of the floor, which is why they considered the shear deformation component a clearer classification parameter. The conclusions of Eivani et al. (2018) could be considered more reliable since they were based on more realistic models. In any case, both these authors and Nakamura et al. (2017b) consider that further studies are required for a more rigorous classification.

Previous studies on how in-plane floor flexibility influences the seismic behavior of buildings focused on showing the difference in behavior of a building with a flexible floor and the same building with a rigid floor (Jain and Jennings 1985; Saffarini and Qudaimat 1992; Ju and Lin 1999). Rigid diaphragms distribute the lateral load proportionally to the stiffness of the walls, whereas in flexible diaphragms the distribution tends to be proportional to the influence area of each wall. However, the most evident effects of increasing the flexibility of the floor system were established from the behavior of the building with a rigid floor: an increase in its fundamental period, a tendency of global modes of vibration to disaggregate into local modes 
and increasing inhibition of torsional components of deformation (Kunnath et al. 1991; Moon and Lee 1994; Tena-Colunga and Abrams 1996; Fleischman and Farrow 2001). Subsequently, studies by Kim and White (2004), Brignola (2009) and Calderini et al. (2012) clarified the mechanism of load transfer between walls and evidenced the implications of a rough estimate of the shear stiffness of floor diaphragms. Overestimating (e.g. an inappropriate fully rigid floor assumption) or underestimating this stiffness would result in an overestimation or underestimation, respectively, of the building's base shear capacity.

In recent years, the study of the influence of floor system flexibility on the seismic behavior of buildings, particularly URM buildings, has focused on low-rise buildings. This is due largely to several studies of this problem that considered mainly general geometric variables such as the number of stories and the aspect ratio and concluded, in the framework of their parametric studies, that floor system flexibility has the greatest impact on the seismic behavior of the lowest rise and highest aspect ratio buildings (Kunnath et al. 1991; Saffarini and Qudaimat 1992; Moon and Lee 1994; Barron and Hueste 2004; Sadashiva et al. 2012). These conclusions were corroborated by Bazarchi et al. (2018), who addressed the problem in relation to steel frame buildings with steel-deck composite floors.

In the most recent literature on floor system flexibility effects on low-rise buildings with symmetric and asymmetric plans, the conclusions refer to aspects such as: 1) global seismic response: modal parameters, interstory drift profiles, base shear and displacement capacity (Giongo 2013; Nakamura et al. 2017a; Kollerathu and Menon 2017; Ortega et al. 2018; Lagomarsino et al. 2018); 2) the lateral load pattern for pushover analysis (Cattari et al. 2015; Lagomarsino et al. 2018); 3) displacement and ductility demands on in-plane walls (Nakamura et al. 2017a; Eivani et al. 2018); 4) in-plane deformability of the floor system in models of low-rise buildings and a review of the normative criteria of diaphragm classification (Tena-Colunga et al. 2015; Nakamura et al. 2017b; Eivani et al. 2018); and 5) 
the applicability of nonlinear static procedures to low-rise URM buildings (Lagomarsino and Cattari 2015b; Nakamura et al. 2017a; Guerrini et al. 2017; Lagomarsino et al. 2018; AziziBondarabadi et al. 2019; Diana et al. 2019; Marino et al. 2019). However, in European built heritage, specifically in the inventory of residential dwellings, high-rise URM buildings are common. This fact was recognized in the RISK-UE project, in which the sub-group of highrise URM buildings was included in the Building Typology Matrix within the URM building class and characterized as having six or more stories (Milutinovic and Trendafiloski 2003). Furthermore, it is common for high-rise URM buildings to have floor plans with a considerable degree of symmetry. For example, this is typical of buildings of the Eixample district of Barcelona. In Gonzalez-Drigo et al. (2017), which investigates the applicability of nonlinear static procedures to high-rise URM buildings, one of these buildings (seven stories, constructed in 1934) is described in detail.

In this context, the paper summarizes a study whose primary objectives were to develop a model for nonlinear static pushover analysis of URM buildings considering floor system flexibility and to analyze the influence of stiffening the floor system on the global seismic response of high-rise URM buildings. To this end, a prototype building (PB) modeled based on a six-story, pre-modernist (1860-1880) building in the Eixample-Barcelona district was adopted as a case study. A composite floor of Steel Beams and Brick Vaults (SBBV-floor), which is characteristic of URM buildings in this district (Lantada 2007), was assumed initially. Under the premise of global failure governed by the in-plane behavior of the walls, a model within the Equivalent Frame approach (EF-approach) was proposed. The floor system was modeled as an aggregation of floor diaphragm macro-elements. The modeling was carried out with the program Ruaumoko (Carr 2007a), which has been widely used for seismic analysis of reinforced concrete and steel buildings, but not in the field of seismic analysis of URM buildings. In this framework, it was found that an EF-model with spring- 
type members (instead of an EF-model with beam-type members) is the most feasible due, mainly, to the possibility of a more adequate description of nonlinear shear behavior in URM walls (Jiménez-Pacheco 2016). In this way, both the walls and floor diaphragm models were developed using the spring elements of Ruaumoko. The construction of the model followed a strategy of modeling and validation by stages, from the two-dimensional (2D) EF-model to the integral model of the PB.

The proposed EF-model was validated, in terms of pushover curves, by adopting as a benchmark the force-displacement curves obtained in widely recognized experimental and simulation studies (Calvi and Magenes 1994; Magenes et al. 2000; Paquette and Bruneau 2003). Since the proposed EF-model does not evaluate the Boundary Conditions of the Piers (BCP), we examined three possibilities (cantilever BCP, fixed-fixed BCP and intermediate BCP) and identified for each of the walls under study the BCP corresponding to the best fit between the obtained pushover curve and the reference force-displacement curve. The results of the pushover analyses were used to assess the influence of the variation in BCP on the characteristics of the pushover curves.

The floor diaphragm macro-element (FDM) and the proposed 3D model (implemented on the PB) were validated by comparing the results obtained with those reported by the Tremuri program (Lagomarsino et al. 2013; Penna et al. 2014). As part of the validation, the PB model was adjusted in terms of the BCP. The analysis of the influence of the stiffening of the floor system on the global seismic response was based on the application of conventional stiffening interventions to the SBBV-floor. Based on a sensitivity analysis, the study focused on three cases: 1) original unstiffened case, 2) a selected stiffened variant and 3) a variant with a fully rigid floor. The overall seismic response was evaluated in terms of the modal parameters, characteristics of pushover curves and the deformed shape of the floors. The results are discussed in the context of recent studies and more general conclusions obtained from 
previous studies (Moon and Lee 1994; Barron et al. 2004; Sadashiva et al. 2012). To enrich the conclusions about the proper functioning of the model, a second application was carried out on the prototype building, assuming a timber floor (also typical in the buildings of the Eixample-Barcelona) and two cases of stiffening: with double orthogonal sheathing and with diagonal strips of carbon fiber-reinforced plastic (CFRP). From the PB results, one conclusion is that for high-rise URM buildings with a high degree of symmetry in plan, stiffening of a flexible floor system (up to a semi-rigid condition) seems to be an appropriate intervention to correct problems of interstory drift profiles exhibiting pronounced variations without generating torsional problems.

\section{DESCRIPTION OF THE PROTOTYPE BUILDING}

\subsection{Architectural and typological aspects}

From the mid-nineteenth century in Barcelona, an intense urbanization process took place that enabled the old part of the city to be integrated with the small villages that currently constitute the city's districts. This process began in 1859 with the approval of the Eixample Plan (also known as the Cerdá Plan). Among the ten districts that currently constitute Barcelona, the Eixample District stands out as the most iconic, especially because of its urban and architectural heritage. About $70 \%$ of the buildings in this district correspond to the brickURM bearing wall typology (Lantada 2007). Among these buildings, the vertical continuity (along the height of the building) of the bearing walls is a relevant differentiating aspect between buildings that exhibit vertical continuity of the bearing walls and those that do not. Paricio (2008) refers to them as first-generation buildings and second-generation buildings, respectively. The latter became the predominant solution at the end of the nineteenth century due to the consolidation of steel technology and the need to free the ground floor of interior walls to facilitate their use in commerce (Lantada 2007; Paricio 2008). In this research, we 
adopted as the object of study a six-story brick-URM building with vertical continuity of bearing walls and an SBBV-floor (Figure 1a), which combines a feature of first-generation buildings (vertical continuity of bearing walls) with a floor system that is more characteristic of second-generation buildings (when steel technology became predominant), belonging to what is known as the pre-modernist period $(1860-1880)$. According to the typological taxonomy of the RISK-UE project (Milutinovic and Trendafiloski 2003), such a building consists of a high-rise URM building and composite slab, labelled M33H. Hereafter we will refer to it as Prototype Building (PB) or unstiffened case: PB-US.

\subsection{Geometric and mechanical characterization of the prototype building}

A study by Vila (1989) was very useful to establish a representative plan of residential buildings in the Eixample. Vila found that the most typical floor plan is one with a central module of a courtyard and stairways and two lateral courtyards, with five spans in the long direction of the building (average span length of $4.85 \mathrm{~m}$ ). Thus, we decided to select from the projects studied by Vila the one with features that best fit those established as typical. Figure 1b shows the geometry and dimensions of the adopted floor plan.

As regards the openings in the façade walls, Vila (1989) found a pattern of proportions, summarized in the square module of Figure 2b, which evidences the architectural regularity of many of the façades of the Eixample's buildings. An average value of $3.20 \mathrm{~m}$ as an inter-axis length of piers defines the generator module, which is applicable to the stories from the second floor. For the height of the ground floor, a value of $4.20 \mathrm{~m}$, the most common value observed in Vila, was assumed herein. Although it does not represent the most typical case, to avoid irregularities, it was decided to maintain the width of the openings in all stories, which resulted in the façade wall shown in Figure 2a. 
Two characteristics of the Eixample's buildings should be noted with respect to the walls: the lateral walls have no openings and the floor plans generally include walls whose function is not structural, but architectural (not represented in Figure 1b). These partition walls, with thicknesses of $10 \mathrm{~cm}$ or even less, are not part of the lateral load resisting system and therefore are not considered in the analysis model. However, their influence in terms of vertical load and mass was considered as an additional load of $100 \mathrm{~kg} / \mathrm{m}^{2}\left(0.98 \mathrm{kN} / \mathrm{m}^{2}\right)$ to the permanent load of the floor system (Gonzalez-Drigo et al. 2015). Finally, the geometric and mechanical characteristics of the walls were adopted based on the comprehensive work of GonzalezDrigo et al. (2015), as detailed in Tables 1, 2 and 3.

A composite steel and masonry slab, SBBV, was adopted as a floor system in this study. It comprises a system of $70-\mathrm{cm}$ spaced IPN-16 beams, the infill is rubble and mortar and the concrete topping is $3 \mathrm{~cm}$ of lime mortar (Figure 3). These characteristics and the indicated values were obtained from Pujades et al. (2012) and Gonzalez-Drigo et al. (2015). The total permanent load associated with this floor was evaluated as $350 \mathrm{~kg} / \mathrm{m}^{2}\left(3.43 \mathrm{kN} / \mathrm{m}^{2}\right)$; the different load contributions are given in Table 4.

\section{MODELING OF THE WALLS}

Under the EF-approach, the walls are represented by an assembly of $1 \mathrm{D}$ or 2D members (piers and spandrels). The models with beam-type members are the most common in the category of EF-models with 1D members, and several of them have even been implemented in specialized or general purpose programs: Tremuri (Galasco et al. 2006; Lagomarsino et al. 2013; Penna et al. 2014), SAM (Magenes 2000; Magenes et al. 2006), SAP2000 (Kappos et al. 2002; Pasticier et al. 2008; Knox and Ingham 2012) and OpenSees (Akhaveissy and Abbassi 2014; Raka et al. 2015). Within the EF approach with 2D members, the most notable model is the one proposed by Caliò et al. (2012), where piers and spandrels are represented as two- 
dimensional nonlinear macro-elements. This EF approach has been subsequently upgraded in order to simulate mixed structures and the out-of-plane masonry walls behavior (Pantò et al. 2017; Pantò et al. 2018).

As a simpler alternative to the EF-models with beam-type members, Chen et al. (2008) and Amadio et al. (2011) proposed EF-models with spring-type macro-elements. Although promising, these alternative models have not been implemented in platforms for seismic analysis. Chen et al.'s model (Chen et al. 2008) consists of a macro-element including an arrangement of an axial spring, three shear springs and two rotational springs. Two shear springs at the top and bottom of the macro-element were added to the central one in order to consider the bed joint sliding. In principle, this macro-element could simulate the seismic behavior of the spandrels; however, in view of the lack of experimental tests (the work cited was published in January 2008), it was only validated for piers. Amadio et al. (2011) proposed an EF model with spring-type macro-elements that can be used in nonlinear analysis of URM buildings under monotonic or cyclic loading. The macro-element proposed by these authors is the same for both piers and spandrels. It includes three springs connected by rigid links: two springs at the ends responding to bending and control rocking failure mode, and the central spring responding to shear forces and control diagonal straight cracking and diagonal stepped cracking failure modes (Figures 4a and 4b). This model was validated by comparing the results with experimental results at both member and wall level. In addition, the validation was enriched by a deeper discussion of the outcomes in Rinaldin et al. (2016). Therefore, this modeling approach can be effectively employed for the practical analysis of URM buildings under seismic loading.

Of the two models mentioned above, we considered the model proposed by Amadio et al. (2011) as the best option, being more comprehensive and more in accordance with the failure modes to be considered. However, it should be noted that the model proposed by Amadio et 
al. (2011) provides an approximate representation of the elastic behavior. It has been proven that, compared to EF-models with beam-type members, the differences in the maximum displacement and fundamental period are usually less than $10 \%$. Such a potential error in the elastic response prediction is often less than the inaccuracy due to the use of an approximate value for the masonry elastic modulus (Rinaldin 2012).

\subsection{Kinematics and mechanical model}

The EF approach applied in the analysis of URM buildings entails replacing the walls with equivalent frames composed of piers and spandrels connected by rigid links. Systematic parametrical analyses (numerical and experimental) aimed to define rigorous criteria for the identification of piers and spandrels in different wall layouts are still lacking (Quagliarini et al. 2017). The identification criterion used in this work is that proposed by Dolce (1991) and illustrated in Figure 4a. Although mainly based on the observation of the damage after earthquakes, this criterion exhibits a certain degree of experimental validation (Quagliarini et al. 2017).

In terms of the composition and kinematic model, the proposed macro-element is the same for

pier and spandrel members, obeying largely the composition and kinematic model of the generic macro-element proposed in Amadio et al. (2011) and Rinaldin (2012). With respect to its implementation, it must be indicated that the spring element of Ruaumoko-2D (Carr 2007b) is a four-node one-dimensional element that comprises two rigid links at the ends and a deformable central part, delimited by the central nodes 3 and 4 shown in Figure 5a. This central part consists of a package of three types of springs: axial, shear and flexural. The axial, shear and flexural forces are proportional to the differences between longitudinal, transverse and rotational displacements (respectively) of the outer nodes 1 and $2(\mathrm{u} 1, \mathrm{u} 2$ and $\varphi$ in Figure 5b). To simulate a rigid-body behavior (avoiding numerical problems) a very high stiffness value is assigned to the corresponding spring. 
Since the macro-element proposed by Amadio et al. (2011) was built with spring elements like those of Ruaumoko-2D, except for the fact that the rigid links are not integrated into the element, its kinematic model was assumed considering this fact in the assembly. Thus, in relation to Figure 4c, depicting a generic macro-element, each spring $i(i=1,2,3)$ works with 3 DoFs per node; nodes I and $\mathrm{J}$ are external, while $\mathrm{n}_{1}$ and $\mathrm{n}_{2}$ are internal nodes. There are in total 4 nodes, with a total number of 12 equations for the linear system presented in Equations (1a) and (1b):

$$
\mathbf{f}=\mathrm{Ku} ; \quad\left\{\begin{array}{l}
\mathrm{f}_{\text {ext, }, 1} \\
\mathrm{f}_{\text {ext, }, 2} \\
\mathrm{f}_{\text {ext }, 3} \\
f_{\text {int }} \\
f_{\text {ext }, 4} \\
f_{\text {ext }, 5} \\
f_{\text {ext }, 6}
\end{array}\right\}=K^{12 \times 12}\left\{\begin{array}{l}
u_{\text {ext }, 1} \\
u_{\text {ext }, 2} \\
u_{\text {ext, }, 3} \\
u_{\text {int }} \\
u_{\text {ext }, 4} \\
u_{\text {ext, },} \\
u_{\text {ext }, 6}
\end{array}\right\}
$$

where $\mathbf{f}$ is the force vector of the generic macro-element, of size 12; $\mathbf{u}$ is the displacement vector of the generic macro-element, of size 12; $f_{\text {ext,k }}$ (with $k=1,2, \ldots 6$ ) are the forces in the external nodes I and $\mathrm{J}$; $\mathbf{f}_{\text {int }}$ is the internal force vector, of size 6 ; $\mathrm{u}_{\text {ext,k }}$ (with $\mathrm{k}=1,2, \ldots 6$ ) are the displacements of the external nodes I and J; $\mathbf{u}_{\text {int }}$ is the internal displacement vector, of size 6; the stiffness matrix of the generic macro-element, $\mathrm{K}$, is formed by the assembly of the stiffness sub-matrices of the springs, $\mathrm{Ks}_{\mathrm{i}}$, as depicted in Figure 6, with $\mathrm{Ks}_{\mathrm{i}}$ given by Eq. (2).

$$
\mathrm{Ks}_{i}=\left[\begin{array}{cccccc}
\mathrm{k}_{\mathrm{N}, \mathrm{i}} & 0 & 0 & -\mathrm{k}_{\mathrm{N}, \mathrm{i}} & 0 & 0 \\
0 & \mathrm{k}_{\mathrm{V}, \mathrm{i}} & 0 & 0 & -\mathrm{k}_{\mathrm{V}, \mathrm{i}} & 0 \\
0 & 0 & \mathrm{k}_{\mathrm{M}, \mathrm{i}} & 0 & 0 & -\mathrm{k}_{\mathrm{M}, \mathrm{i}} \\
-\mathrm{k}_{\mathrm{N}, \mathrm{i}} & 0 & 0 & \mathrm{k}_{\mathrm{N}, \mathrm{i}} & 0 & 0 \\
0 & -\mathrm{k}_{\mathrm{V}, \mathrm{i}} & 0 & 0 & \mathrm{k}_{\mathrm{V}, \mathrm{i}} & 0 \\
0 & 0 & -\mathrm{k}_{\mathrm{M}, \mathrm{i}} & 0 & 0 & \mathrm{k}_{\mathrm{M}, \mathrm{i}}
\end{array}\right]
$$


Ruaumoko uses a Newton-Raphson iteration at each step of the pushover analysis to eliminate residual forces resulting from the change in the stiffnesses of the springs constituting the generic macro-element. This ensures a satisfactory equilibrium and, therefore, the vector $\mathbf{f}_{\text {int, }}$ which collects the forces at the ends of the central spring, is practically a zero vector. The axial, shear and flexural stiffnesses for the spring $i(i=1,2$, 3; Figure 4c) are given in Equations (3), (4) and (5), respectively. Infinite stiffness values ( $\mathrm{k}_{\mathrm{v}, 1} \mathrm{k}_{\mathrm{v}, 2}$ and $\left.\mathrm{k}_{\mathrm{M}, 3}\right)$ should be understood as very high values, and simulate rigid-body behavior.

$$
\begin{aligned}
& \mathrm{k}_{\mathrm{N}, \mathrm{i}}=3 \frac{\mathrm{EA}}{\mathrm{H}_{\mathrm{d}}} \text { for } \mathrm{i}=1,2,3 \\
& \mathrm{k}_{\mathrm{V}, \mathrm{i}}=\infty \text { for } \mathrm{i}=1,2 \text { and } \mathrm{k}_{\mathrm{V}, 3}=\frac{1}{\frac{\mathrm{H}_{\mathrm{d}}^{3}}{12 \mathrm{EI}}+\frac{\chi \mathrm{H}_{\mathrm{d}}}{\mathrm{GA}}} ; \frac{1}{\frac{\mathrm{H}_{\mathrm{d}}^{3}}{3 \mathrm{EI}}+\frac{\chi \mathrm{H}_{\mathrm{d}}}{\mathrm{GA}}} \\
& \mathrm{k}_{\mathrm{M}, \mathrm{i}}=\frac{8 \mathrm{EI}}{\mathrm{H}_{\mathrm{d}}} \text { for } \mathrm{i}=1,2 \text { and } \mathrm{k}_{\mathrm{M}, 3}=\infty
\end{aligned}
$$

where $\mathrm{E}$ is the modulus of elasticity of the masonry, A is the area of the element cross-section of the URM panel (pier or spandrel), $H_{d}$ is the deformable length of the URM panel (pier or spandrel), G is the shear modulus of the masonry, I is the moment of inertia of the crosssection of the URM panel (pier or spandrel) and $\chi=1.2$ is the form factor for rectangular sections.

Boundary Conditions of the Piers (BCP) affect both elastic stiffness and strength capacity of the piers. The evaluation of the BCP is based on the height to the contraflexure point in the piers, and can represent a difficulty, especially within the framework of the spring-type EFmodel. Amadio et al. (2011) do not consider the effect of the BCP on the elastic stiffness of the piers. We consider this effect with the Equations (4a) and (4b), recommended by the 
FEMA 356 (2000) and adopted in codes such as ASCE/SEI 41-17 (2017) for the lateral inplane stiffness of piers under fixed-fixed or cantilever boundary conditions, respectively. In addition, assuming these two BCP as limit cases, an intermediate BCP (which tries to capture the case of piers with contraflexure point of average value between the corresponding ones of the piers with a BCP limit) was taken into account assigning to such piers a stiffness equal to the average value of the stiffnesses given by the Equations (4a) and (4b). Thus, the proposed EF-model requires a priori assignment of BCP which depends on the criteria of who implements the model. The proposed characterization of the limit cases of the BCP represents (in this specific aspect) an improvement over the approach presented in Amadio et al. (2011) and has led to acceptable approximations (see section 3.3.2). However, it can be refined through a parametric study, varying the coefficients of the simple stiffnesses of the shear and flexural springs.

\subsection{Nonlinear modeling of piers and spandrels}

\subsubsection{Failure modes and strength capacities of piers and spandrels}

The failure modes considered for the piers and spandrels of the model are summarized in Table 5 together with the formulas used to evaluate the corresponding strength capacities. The formulas proposed in Magenes and Calvi (1997), adopted by codes such as the NZSEE (2006), were assumed here for the piers. The limit of 2.5 proposed by Magenes and Calvi (1997) for the correction factor $\left(1+\alpha_{\mathrm{v}}\right)$ was modified based on research by Cattari et al. (2015), as shown in Figure 7. On the other hand, the formula proposed by FEMA 306 (1998) for strength capacity against bending failure and those proposed by Magenes (2000) and Magenes et al. (2000) for strength capacities against shear failure modes were assumed for the spandrels. 
The shear strength capacity of the members was evaluated using the lowest strength capacity associated with the failure modes considered in each case. In the case of the piers: $V u_{p}=$ $\min .\left\{V_{d}, V_{d, b}, V_{s s}\right\}$ and in the case of the spandrels: $V u_{s p}=\min .\left\{V_{s p 1}, V_{s p 2}\right\}$, where $V_{d}, V_{d, b}, V_{s s}$, $V_{s p 1}$ and $V_{s p 2}$ are defined in Table 5. The axial load interactions were not considered. Thus, in the formulas of the strength capacity for the piers, their vertical static load was assumed as the axial force, and in the formulas of the strength capacity of the spandrels, the axial force was set as equal to zero. We are aware that this is an important limitation, particularly for high-rise URM buildings: in future work we will seek to overcome it.

\subsubsection{Force-displacement relationships of the spring components of piers and spandrels}

In the framework of the European project PERPETUATE (Lagomarsino et al. 2012; Lagomarsino and Cattari 2015a), Cattari et al. (2012) proposed multi-linear forcedisplacement relationships (FDRs) that could describe the nonlinear shear and flexural response of piers and spandrels up to severe damage levels. These FDRs considered five damage states, characterized by a drift $\delta$ and a percentage of degradation $\beta$ (stepped degradation). Recommended use ranges for these parameters are given in Cattari et al. (2012). Based on these guidelines, and assuming average values for $\delta$ and $\beta$, referential FDRs were delineated (multi-linear FDRs with a dotted line in Figures 8 and 9). The FDRs of the proposed EF-model were established from these referential FDRs, combining bi-linear and tri-linear FDRs with the bi-linear strength degradation law of Ruaumoko (Carr 2007d).

Regarding the FDRs of the members, the shear FDR was built so that the areas under their degrading portions equaled the areas under the degrading portions of referential shear FDRs (multi-linear FDRs with a continuous line in Figures 8a and 9a). In contrast, the flexural FDRs were defined more simply, so that they exhibit only one degradation phase until a residual strength is reached (multi-linear FDRs with a continuous line in Figures 8b and 9b). 
The tri-linear portion in the shear FDR was adopted to consider the first cracking, assuming a post-cracking stiffness equal to 35\% of the elastic stiffness.

The FDRs of the spandrels were based on the experimental work of Gattesco et al. (2008), as their results refer to spandrels that share basic features with those considered in this study: old brick masonry and timber lintel. Consequently, a residual strength of $0.4 V_{\max }$ was adopted for the referential FDRs. In the case of the flexural FDR (Figure 9b), a linear degradation was adopted as it fits better than the stepped one with the experimental curve obtained by Gattesco et al. (2008).

\subsection{Applications with the proposed Equivalent Frame model}

\subsubsection{Characterization of the study cases}

Three studies were considered to validate the proposed EF-model: 1) tests performed by Calvi and Magenes (1994) on a two-story prototype building at the University of Pavia, 2) simulations carried out, as part of the Catania project, on a selected wall of the building in Via Verdi (Liberatore and Spera 2000; Magenes et al. 2000; Amadio et al. 2011) and 3) a fullscale single-story URM building tested in the laboratory by Paquette and Bruneau (2003). The main outcomes for comparative purposes were the force-displacement curves under lateral loads obtained experimentally as backbone curves or by numerical simulation (in the case of wall D, the Catania project). In this context, pushover analyses were performed on four walls: the Pavia walls including the known door-wall and window-wall (Calvi and Magenes 1994), wall D of the building in Via Verdi (Magenes et al. 2000) and the west wall in a building tested by Paquette and Bruneau (2003). Figures 10, 11, 12 and 13 show the walls' dimensions, discretization, nodal masses and the vertical loads on the piers. Table 6 shows their mechanical properties.

\subsubsection{Pushover analysis of the walls and discussion of results}


The pushover analysis on the four walls had two fundamental objectives: 1) to show the effect of the BCP on the characteristics of the pushover curves that were obtained, considering the three named BCP (cantilever, intermediate and fixed-fixed) as in the previous sections, and 2) to identify among the BCP those whose pushover curves constitute the best approximation to the reference curves. At pier level, the effect of the three BCP on the elastic stiffness and strength capacity was considered, as described in Sections 3.1 and 3.2.1, respectively. With respect to wall $\mathrm{D}$ of the Catania project, given the significant sensitivity of its forcedisplacement response to the variation in the lateral load pattern (Magenes et al. 2000), its analysis included two cases differentiated by the lateral load pattern. GE (see Table 7) represents the ratios between the seismic force on the floor and the base seismic shear. Table 7 summarizes the characteristics of the pushover analyses for each of the five cases studied. In terms of drift, the FDRs used in the nonlinear modeling of piers and spandrels of the walls are represented in Figures 8 and 9.

Figures 14, 15 and 16 show the sets of three pushover curves (BCP of 0.5, 0.75 and 1 ) for the five cases described in Table 7, together with the reference curve (see Table 7). Figure 16b, corresponding to the wall tested by Paquette and Bruneau (2003), represents a magnified version (in terms of displacement) of Figure 16a, to show the variation in the elastic stiffness of the pushover curves. The curves were developed until they showed a $20 \%$ decay in base shear capacity, apart from the curve corresponding to the Pavia prototype's door-wall (Figure 14a), which is shown as fully developed to illustrate the pushover curve originally reported by Ruaumoko.

Thus, from a general examination of Figures $14 \mathrm{a}$ to $16 \mathrm{~b}$, it can be stated that, with the increase in value of the BCP, that is, with the passage from the fixed-fixed to cantilever condition, the following occurs: 1) a decrease in elastic stiffness, 2) a decrease in base shear capacity, and 3) an increase in displacement capacity. Concerning Paquette and Bruneau's 
wall, its very ductile failure mode (combination of failure modes by bending and bed joint sliding on its piers) meant that this third effect could not be evidenced. Figures 17 and 18, where the values of elastic stiffness, base shear capacity and lateral drift are represented against BCP, show that for each wall this variation was very close to linear and, in the case of elastic stiffness, the rate of decrease remained practically constant. In addition, it was considered pertinent to add to Figures 17 and 18 the results of Dolatshahi et al. (2018), on the influence, at pier scale, of the BCP in the characteristics of the force-displacement curves under lateral load. From a parametric study of simulation with a finite elements model, such results were presented as series of ordered pairs. The best fit lines show that the influence of the BCP on the force-displacement behavior of the walls considered (with a regular pattern of openings) is the same as at the pier scale; the rate of variation is even maintained regarding elastic stiffness and lateral drift.

Another basic objective was to identify in the cases analyzed the BCP of the proposed EFmodel that led to the best approximation between the obtained pushover curve and the corresponding reference curve (see Table 7). Considering the limitations of the model (e.g. the omission of interactions with the axial force in the modeling of the members), it could be said that the BCP that best represent the Pavia and Catania walls are the intermediate BCP and the fixed-fixed BCP, respectively. The results for Paquette and Bruneau's wall are less clear: probably the best option is a BCP between intermediate and fixed-fixed. In any case, these best fit curves show considerable agreement with the reference curves, especially with those of Amadio et al. (2011), as shown in Figure 15b. The latter should be expected, not only from the similarities of the EF-models but also from the assumption of a fixed-fixed BCP in Amadio et al. (2011). For the sake of showing the consistency of the adjustment achieved through the BCP, it is pertinent to note that, in Calderini et al. (2009), the Pavia prototype's door-wall was studied in detail. In this work, the variation of moments along the deformable 
height of the piers is depicted, and it can be verified (from the contraflexure points) that four of the six piers (including the bottom three, which are responsible for the collapse mechanism) have intermediate BCP. On the other hand, it is plausible to assume that, indeed, the BCP for the Catania wall D is very near to fixed-fixed, since the SAM program, through which the reference curve in Figure 15a was obtained, updates with each step of the pushover analysis the shear spans values (and the axial loads on piers).

In this context, in Jiménez-Pacheco (2016), from the pushover curves of best fit with the reference curves, several outcomes that confirm the proper functioning of the proposed EFmodel were presented; namely: 1) a comparative analysis with the pushover curves obtained by other authors, 2) an adjustment in terms of displacement capacity with the experimental curves of the Pavia walls, 3) the ultimate state of the FDRs that are more developed in members of the Pavia prototype's door-wall. Regarding the comparative analysis of pushover curves, the curves obtained for the walls used as a benchmark showed good agreement with the curves reported by other authors (discrepancies in elastic stiffness, base shear capacity and displacement capacity of less than $15 \%$, mostly between $5 \%$ and $10 \%)$. The adjustment in terms of displacement capacity with the experimental curves of the Pavia walls was reached with the assumption of shear failure drifts for the piers that were very close to those obtained by Galasco et al. (2006).

In terms of the ability to capture the damage, results are presented for the Pavia-DW and the Catania_Wall-D-a (see Table 7). Thus, when the final damage scenario for the Pavia prototype's door-wall (Calvi and Magenes 1994) is compared with the ultimate state of the FDRs on the proposed EF-model (Figure 19a), a good correlation can be appreciated in the piers' behavior. However, in the case of spandrels, the proposed EF-model underestimates to some extent the damage to the door-wall, namely: moderate to severe (Calvi and Magenes 1994). 
On the other hand, we established the collapse mechanism of the Catania_Wall-D-a (Table 1) through the state of the more developed FDRs (Figure 19b). In this regard, studies that address the seismic behavior of Catania_Wall-D-a were examined, finding an important agreement in the results obtained in Pantò (2003), Pasticier et al. (2008) and Rinaldin (2011): global failure dominated by the flexural failure of the upper piers. That the collapse mechanism of the piers is governed (despite their robustness) by the flexural behavior, and is associated with fixed-fixed BCP rather than cantilever BCP, can be explained by the damage verified in the spandrels. Cattari and Beyer (2015) studied the influence of the spandrels on the seismic behavior of regular URM walls. Using an enhanced version of Tremuri, they proved that such influence is particularly important when early damage is verified in the spandrels (weak spandrels), since this would imply the change of fixed-fixed BCP to cantilever BCP. So, it should not be strange that robust piers fail showing flexural cracking, which is more common in slender piers. In fact, in small historic centers such as L'Aquila and Castelvecchio Subequo (Central Italy), the collapse mechanism exhibited by the Catania_Wall-D-a: upper piers with significant flexural damage and the spandrels in the bases of such piers with severe flexural or shear damage (Figure 19b), was reported among the most typical in the façade walls after the Abruzzo earthquake in 2009 (Kouris et al. 2010; Indirli et al. 2013; Bucchi et al. 2013; Brando et al. 2017). It must be noted that many of these buildings had been subject to interventions to avoid out-of-plane failures and favor a boxbehavior (Indirli et al. 2013).

Finally, it should be reiterated that in the proposed EF model the assignment of a single value of BCP to the piers of a URM wall (or building) is an aprioristic assumption that attempts to capture a predominant or "average” BCP in such wall. This assumption would be acceptable to the extent of the regularity in the layout of openings on the walls. Keeping in mind that variables such as the location of the piers, the type and size of openings influence the BCP, 
parametric studies that take these variables into account and provide criteria for assigning BCP would be very useful for the proposed simplified model.

\section{FLOOR DIAPHRAGM MODELING}

\subsection{Classification of floor diaphragms}

The deformed shape of flexible floor diaphragms can be decomposed into four components: two rigid-body motions of translation and rotation, and two deformational modes of shear and bending. The classification of the floor diaphragms into three categories: rigid, stiff and flexible, based on the overall aspect ratio and on the index of flexibility $\Delta_{\mathrm{D}} / \Delta_{\mathrm{W}}$ (Figure 20), is the most widespread (FEMA 273 1997; FEMA 356 2000; ASCE/SEI 7-10 2010; ASCE/SEI 41-13 2014; BHRC 2015; NZSEE 2017; ASCE/SEI 41-17 2017). In practice, it has proven to be rather ambiguous and unreliable. It does not adequately describe the behavior of the floor system in terms of components of deformation and it may lead to an unreliable distribution of the seismic lateral load between resistant substructures: frames or walls (Moeini and Rafezy 2011; Zahrai and Sarkissian 2015; Tena-Colunga et al. 2015; Koliou et al. 2016; Srisangeerthanan et al. 2018; Halici et al. 2018; Bazarchi et al. 2018; Bahar et al. 2019). Several research groups have addressed this problem, finally raising their own classification schemes of floor systems (Tena-Colunga et al. 2015; Nakamura et al. 2017b; Eivani et al. 2018). Although all the works coincide, in that further studies are still required for a more rigorous classification, it is worth highlighting that of Eivani et al. (2018). This work, based on a parametric study on idealized symmetric and asymmetric single-story models, revealed a remarkable greater shear deformation sensitivity of the floor diaphragms to the asymmetry and flexibility degrees, concluding that the shear deformation constitutes a clearer classification parameter. 


\subsection{Shear stiffness of the floor diaphragm: proposal}

A robust classification of floor diaphragms should allow us to determine, in terms of deformations, which deformation component dominates the floor system response of a building subjected to seismic action. In the scope of the seismic assessment, this information would be very useful to implement simpler, more effective modeling strategies. Consequently, the conclusions of Tena-Colunga and Eivani would have more practical implications due to the more realistic characteristics of their analysis models. When the results are analyzed together, and considering the conclusions of other studies (Kim and White 2004; Brignola et al. 2009; Brignola et al. 2012; Tena-Colunga et al. 2015; Giongo et al. 2016; Halici et al 2018; Bazarchi et al. 2018; Ortega et al. 2018), it is evident that three local variables are determining factors in the deformability of the floor diaphragms: size, aspect ratio and chorded or unchorded condition. Moreover, under a seismic lateral load, buildings with an aspect ratio of less than 2.5 and a non-rigid floor system (negligible torsional rotation), when the floor diaphragms are not large (a shorter length of less than $6 \mathrm{~m}$, approximately) and the aspect ratios are not high (less than 2, approximately), experience deformations in which the shear component is dominant, and more clearly dominant if the floor diaphragms are unchorded.

In the USA, New Zealand and Australia, URM buildings with floor systems constituted of large chorded diaphragms and aspect ratios of two or more are common (Brignola et al. 2012; Wilson 2012; Giongo 2013; Wilson et al. 2014). Under seismic action, these features favor a deformed shape of the floor dominated by the bending component. Conversely, the floor diaphragms considered in this study (in addition to being part of a building with an aspect ratio of less than two) are smaller, with an aspect ratio of less than 1.5 and without chord members on their edges (Vila 1989; Paricio 2008). Consequently, it is reasonable to expect a deformed shape exhibiting a shear component that is clearly dominant. Finally, it is known 
that floor system flexibility tends to inhibit the torsional deformation component (TenaColunga and Abrams 1996; Brignola 2009; Magenes et al. 2014; Senaldi et al. 2014; TenaColunga et al. 2015; Nakamura et al. 2017b; Lagomarsino et al. 2018). According to Nakamura et al. (2017b), this component is very small for stiff floor diaphragms and negligible for semi-flexible and flexible floor diaphragms.

Thus, thinking of a floor diaphragm with simple orthotropic behavior, which is limited to translational motions and shear deformations, an ideal thin plate subjected to lateral loading (Figure 21a) was outlined as a first approximation. Its shear stiffness $\left(\mathrm{K}_{\mathrm{d}}\right)$, established as the force F required to produce a lateral displacement $\Delta=1$, was calculated as follows:

$$
\begin{aligned}
& \mathrm{G}=\frac{\tau}{\gamma} ; \mathrm{G}=\frac{\chi \mathrm{FL}}{\mathrm{Bt} \Delta} ; \frac{\mathrm{F}}{\Delta}=\mathrm{K}_{\mathrm{d}} \\
& \mathrm{K}_{\mathrm{d}}=\frac{\mathrm{GBt}}{\chi \mathrm{L}} ; \mathrm{K}_{\mathrm{d}}=\frac{\mathrm{G}_{\mathrm{eq}} \mathrm{Bt}}{\chi \mathrm{L}}
\end{aligned}
$$

where $\mathrm{B}$ is the dimension of the diaphragm parallel to the load; $\mathrm{L}$ is the dimension of the diaphragm perpendicular to the load; $t$, the thickness of the diaphragm; $G$ is the shear modulus of an ideal homogeneous plate; $\chi=1.2$ is the shear factor for rectangular sections; $\mathrm{G}_{\text {eq }}$ is the shear modulus of the floor diaphragm idealized as an equivalent homogeneous plate.

It is important to note that Equation (7b) for the evaluation of the lateral stiffness of the FDM assumes three premises: 1) the wall-diaphragm connection is assumed in the best conditions, therefore the connectors would be rigid and the overall deformation is only due to the internal diaphragm stiffness, 2) the horizontal distribution of seismic forces is verified only through the walls constituting the lateral load resisting system, and 3) under the action of lateral loads, the floor diaphragm responds to the seismic action in the elastic field. Under these assumptions, and in a macro-modeling context, the equivalent shear modulus, $\mathrm{G}_{\text {eq, }}$, represents 
the most important modeling parameter of the floor diaphragm (with a view to seismic analysis). Its evaluation must consider a mechanism of horizontal distribution of seismic forces. The one adopted here (seismic forces transferred only through the walls) has been assumed by authors such as Brignola et al. (2009) and by guidelines such as SDI (1995), and is consistent with the setup of several tests on square specimens of timber or SBBV-floors (Corradi et al. 2006; Valluzzi et al. 2013; Branco et al. 2013; Gattesco and Macorini 2014; Shakib et al. 2015).

The evaluation of the $\mathrm{G}_{\text {eq }}$ parameter, which represents the shear modulus of the floor system idealized as a homogeneous plate of constant thickness, can be analytical or experimental. The analytical way consists in solving for $G_{\text {eq }}$ the equation of equality of two lateral displacements: one obtained under the assumed idealized conditions (e.g. Eq. (7b)), and the other derived from the mechanics of materials, considering the different contributions of deformation. In the contribution of shear deformation, attributable to one of the components of the floor system, intervenes the shear modulus, $G$, which should not be confused with $G_{\text {eq. }}$. By way of illustration, the first part of the work of Brignola et al. (2009), about the in-plane stiffness of single straight sheathing timber floors, addresses the analytical deduction of a formula for $\mathrm{G}_{\mathrm{eq}}$; in this deduction, $\mathrm{G}$ refers to the shear modulus of timber planks, a parameter associated with the board shear deformation (one of the three contributions of deformation considered; see section 6.3.1). Regarding the experimental way, $\mathrm{G}_{\text {eq }}$ is evaluated from the equation of the diaphragm idealized as a homogeneous plate under an assumed lateral load condition (e.g. Eq. 5(b)), using the stiffness of the diaphragm obtained experimentally. All sources of deformation (shear and flexural deformations of the system, deformation of the anchorages at the diaphragm boundaries, etc.) are included within the stiffness values derived from tests. The results of the tests on floor diaphragm specimens serve as a benchmark for the validation of analytical formulations (e.g. lateral displacement, $\mathrm{G}_{\mathrm{eq}}$ ) and are decisive for those 
floor systems that do not have satisfactory analytical studies to evaluate $G_{\text {eq. }}$. The latter is common in composite floors, such as the SBBV-floor studied herein, or the current lightweight floor systems, including cold-formed steel joists and wood-based floor panels (Kyvelou et al., 2017; Ahmed and Tsavdaridis 2019). Moreover, the tests described in the literature (Giongo 2013; Gubana 2015) refer to different setups, boundary conditions, aspect ratio of the floor specimens and recorded parameters, which makes the task of comparing the results difficult. In particular, for comparative purposes, it is important to be clear about the type of stiffness obtained experimentally: initial tangent stiffness or secant stiffness, and in this latter case, its criterion.

To capture with Ruaumoko the behavior illustrated in Figure 21a without resorting to its quadrilateral membrane element, which would have made the model's implementation too complex (Nakamura et al. 2017b), a much simpler spring-based macro-element was proposed. The FDM, comprising two shear springs and two axial springs placed along the edges of the span as parallel arrangements, is schematized in Figure 21b. With the main focus on unidirectional floor systems, two additional simplifications were assumed in this study: 1) the floor diaphragm responds in the elastic range, and 2) the axial stiffness of the floor diaphragm is considered infinite. Regarding the first simplification, although timber diaphragms can exhibit large deformations, the energy dissipation is limited, and the strength degradation does not usually occur at these levels of deformation (Giongo et al. 2014). Hence, the assumption of an elastic response for the floor diaphragm can be considered appropriate. Regarding the second simplification, it has been found for this type of floor system that the axial stiffness is much greater than the shear stiffness (Peralta et al. 2000; Kim and White 2004), so several authors have decided to assume an infinite axial stiffness and neglect the possibility of elongation and shortening (Kim and White 2004; Park et al. 2009). However, the solution shown in Figure 21b, when implemented in Ruaumoko using its spring element, allows a 
simple consideration of the orthotropic behavior exhibited by unidirectional floor systems. Considering that this type of element comprises (in 3D) a pack of six springs with the potential to control deformability according to six degrees of freedom (Carr 2007c), each pair of springs of the arrangements is modeled so that they respond both axially (without allowing deformation) and to shear. Thus, when the orthogonal direction of the lateral load is changed, the pair of spring-elements that worked as axial springs stops doing this to work as shear springs and vice versa.

\subsection{Validation of the proposed floor diaphragm macro-element}

\subsubsection{Preliminary considerations: Tremuri program and floor diaphragm-walls assembly}

We adopt 2D models of the wall and the floor diaphragm as a modeling strategy to study the behavior of a simple building, which can be used as a baseline to implement a more realistic URM building model. Although a more rigorous way would have been to assume as a benchmark an experimental or micro-modeling based simulation, those found in the literature

(e.g. Bothara et al. 2010; Lourenzo et al. 2011; Mendes et al. 2014; Senaldi et al. 2014; Ortega et al. 2018; Kallioras et al. 2018; Esposito et al. 2019) were not pertinent or not sufficiently simple or representative of the URM buildings to be modeled (solid brick walls, non-rigid floor system, relatively small spans and an aspect ratio of less than two). Due to an awareness of this pending task, we decided to use the alternative way of comparing our pushover analysis results with those obtained by the Tremuri program (Lagomarsino et al. 2013; Penna et al. 2014). The well-known two-story, one-span building prototype tested by Calvi and Magenes (1994) was adopted as a case study.

Regarding Tremuri, its discretization of the walls in piers and spandrels combines our own criteria with Dolce's proposal (1991) to establish the effective height of the piers. The steps of the equivalent frame idealization procedure are described in Lagomarsino et al. (2013), for 
both regularly and irregularly distributed openings. The behavior of flexible diaphragms is simulated by means of an orthotropic membrane, which can be constituted of 3 or 4 nodes, with two translational degrees of freedom at each node (Lagomarsino et al. 2008; Lagomarsino et al. 2013). Concerning the present study, the Tremuri’s EF-model shares with the proposed EF-model several simplifying assumptions, namely: 1) the failure modes considered for both piers and spandrels are the same, 2) the flexural behavior of the diaphragms and the out-of-plane response of the walls are not evaluated because they are considered negligible with respect to the global building response, and 3) the floor diaphragms respond in the elastic range. On the other hand, Tremuri’s EF-model has features that make it more refined and, therefore, an appropriate benchmark, namely: 1) more rigorous consideration of the BCP (from an estimation of their contraflexure point) and the influence on their force-displacement behavior, 2) consideration of interactions with the axial force in the evaluation of the strength capacities of the members, 3) ability of the membrane element to consider the torsional component of deformation. In this sense, Tremuri has proven its robustness by comparing its seismic analysis results with those obtained by advanced programs such as 3DMacro or finite elements programs such as DIANA (Marques and Lourenzo 2011; Caliò et al. 2012; Marques and Lourenzo 2014; Cattari et al. 2015) or with those obtained from shaking table tests on full-scale masonry buildings (Penna et al. 2015; Nakamura et al. 2017a; Azizi-Bondarabadi et al. 2019).

\subsubsection{Implementation and validation of the basic 3D model}

The implementation of the basic 3D model consists mainly of the assembly of the floor diaphragm and the walls or, more specifically, the assembly of the FDM and the equivalent frames. This operation is schematized in Figure 22, taking advantage of the case study (Figure 22b shows the resulting 3D frame). In the first instance, it should be noted that when the FDM is supported on the equivalent frames, the piers' axes divide their simple springs into 
arrangements of $n+1$ springs (where $n$ : number of axes of piers). Figure 22a shows the local axes of the members and the controlled degrees of freedom (including rigid-body motions, simulated with springs of infinite stiffness). Under the premise of in-plane behavior of the floor diaphragms and the walls, the degrees of freedom controlled at $2 \mathrm{D}$ level in piers and spandrels were maintained at 3D level (i.e. only the in-plane behavior of the members is controlled), the possibility of torsional rotation was not considered for any of the members (piers, spandrels and FDMs) and the three translational degrees of freedom for the FDMs springs were admitted, although with different purposes: horizontal-shear, to control shear deformation; horizontal-axial, to inhibit axial deformation; and vertical, to tie it to the axial degree of freedom of the piers. In addition, Figure 22a shows the functioning of the FDM under seismic lateral loading in the direction of the walls with openings (door-wall and window-wall). The springs in series along the edges of walls parallel to the direction of the lateral load respond only with their axial springs as a rigid body, without giving rise to axial deformation. At the same time, the springs corresponding to the edges of walls perpendicular to the direction of the lateral load (one on each edge) respond only to shear, with shear stiffness established according to the floor system and the direction of the lateral load (with respect to the joists). Finally, orthotropic behavior can be considered simply. In the case that is illustrated, when the direction of the lateral load is changed, that is, if the lateral load acts on the lateral walls (following the direction of the joists), the springs along the edges of the walls would interchange their modes of response: springs along the edges of the door-wall and window-wall would respond to shear, while springs along the edges of the lateral walls would respond axially.

To prove the proposed 3D model, we adopted a SBBV-floor for the Pavia prototype (Figure 23a). The brick vaults rest on a set of joists (IPN140) spaced at $60 \mathrm{~cm}$. A concrete topping (3cm thickness) and a hydraulic pavement floor were assumed. The permanent load associated 
with this solution was evaluated as $3 \mathrm{kN} / \mathrm{m}^{2}$, and with the adoption of a live load of $2 \mathrm{kN} / \mathrm{m}^{2}$ (residential use), the total load was $5 \mathrm{kN} / \mathrm{m}^{2}$. The load transfer mechanism, designed for unidirectional floor systems, is illustrated in Figure 23b. Considering that the concrete topping confers the condition of stiffening to the SBBV-floor and that the lateral load on the Pavia prototype is perpendicular to the joists, a shear stiffness of $3000 \mathrm{kN} / \mathrm{m}$ was used in the 3D model. This value was obtained from an experimental study by Mahdizadeh et al. (2012), designed to investigate the efficacy of replacing the mortar layer with a concrete topping as a stiffening intervention. Figure 24 shows the models of the Pavia prototype displayed by the Ruaumoko and Tremuri programs.

To capture the flexibility of the floor diaphragm, we obtained pushover curves under a lateral load proportional to the first mode and using two displacement control nodes: one on the door-wall and another on the window-wall (nodes 1 and 2 in Figure 24b, respectively). Figure 25 presents the "PR model” curves, obtained using the proposed model (implemented in Ruaumoko), and the "TR model” curves, obtained using Tremuri. The "PR model” curves were obtained using two BCP: cantilever and fixed-fixed. As expected, considering the results obtained on the Pavia walls (Figures 14a and 14b), the best approximation with the TR model was reached under the intermediate BCP. The discrepancies in base shear capacity of approximately $10 \%$ (Figures 25a and 25b) are due to the difference in the formulations to evaluate the shear strength capacity of the piers and the omission of interactions with the axial load in the evaluation of such strength capacities. The discrepancies in elastic stiffness, derived basically from differences in the discretization of the walls and the type of element used in the models, can be considered negligible in this case. The displacement capacities (measured just before the strength degradation) of the PR model and TR model reached values very close to each other. The small discrepancy that can be appreciated is due to the assumption of different shear failure drifts $(0.45 \%$ in the PR model, $0.4 \%$ in the TR model). 
Thus, the difference in lateral displacements between walls in the PR model (intermediate BCP) and the TR model remains practically the same. Hence, it can be considered that the proposed 3D model, incorporating a simple FDM, acceptably captures the flexibility of the floor system.

\section{MODELING OF THE PROTOTYPE BUILDING}

\subsection{Walls: adjustments on the equivalent frame model}

The geometric and mechanical characterization of the PB's walls was discussed in Section 2.2. However, the geometry of the walls used to validate the proposed EF-model was simple: the floor axes coincide with the centroidal axes of the spandrels. In the case of the PB, this coincidence is not verified. Figure 26 shows the solution adopted for a façade wall and an interior wall (axis 4 in Figure 1b). However, the PB's lateral walls have no openings. For the modeling, first we established as a pier the portion of wall between two consecutive orthogonal walls, with its axis placed in the middle of this portion of wall. Second, the lack of openings involved cancellation of spandrels, so that the frames of these walls were formed by the piers and the edge springs of the floor diaphragms.

\subsection{Floor system}

\subsubsection{Steel beam and brick vaults floor: single floor diaphragm}

The SBBV-floor (also known as jack arch masonry slabs or masonry flat arch diaphragms) shown in Figure 3 is representative of those found in many of the Eixample's buildings. The weaknesses of this floor system prevent an effective diaphragm action and complicate significantly how a formula is obtained to evaluate its shear stiffness (Maheri 2004). Faced with this difficulty, the entire research effort on SBBV-floors has been focused on the experimental evaluation of shear stiffness. Thus, Shakib and Mirjalili (2010) conducted an 
experimental study to evaluate the effect of the inclusion of transverse joists (as a method of stiffening intervention) on the seismic performance of an SBBV-floor. They conducted tests in which they applied cyclic lateral loading on full-scale specimens $(3.6 \mathrm{~m} \times 3.6 \mathrm{~m})$ in the two orthogonal directions. The setup of these tests was basically that of Zahrai et al. (2006), in which predominant behavior of simple shear in the two orthogonal directions was established. Seismic performance results were obtained from the backbone envelope of the curves of base shear capacity against lateral displacement. Table 8 shows the results corresponding to the unstiffened SBBV-floor (with loading perpendicular to the joists and parallel to the joists).

\subsubsection{Floor system: assembly process}

The unidirectional floor system of the PB was conceived as the aggregation of floor diaphragms so that their beams cover the shortest span length in each room. Then, each floor diaphragm, modeled as the proposed FDM, was characterized by its shear stiffnesses in the two orthogonal directions, as explained in Section 4.2. The assembly of these basic macroelements with the frames representing the walls causes the segmentation of the springs forming the basic macro-elements in points that intersect with the axes of piers. The subsprings that are generated form arrangements in series, so that the stiffness of each sub-spring is equal to $n$ times the stiffness of the corresponding edge spring $\left(1 / 2 K_{a}\right.$ or $\left.1 / 2 K_{s}\right)$, where $n$ is the number of sub-springs. In addition, the adjacency conditions of the floor diaphragms must be considered. In general, the floor systems of old URM buildings are unidirectional and have no continuity in their supports. In this situation, the sub-springs of the adjacent diaphragms overlap in their common edge and function as in parallel arrangements, giving rise to local stiffening of the floor system (Figure 27a).

The process described above refers to the behavior of the floor system in one of the orthogonal directions. Orthotropic behavior is expected in unidirectional floor systems. The 
orthotropic character of the SBBV-floor is clearly evidenced by its simple shear behavior in the two orthogonal directions (Table 8), and the FDM can capture it, as shown in Figure 27b. The stiffnesses of the diaphragms were determined using Eq. (7b). Previously, the $G_{e q}$ in each orthogonal direction was calculated from Eq. (7b), with the experimental values of Table 8 and assuming $t=8 \mathrm{~cm}$. The definitive values of shear stiffness for the sub-springs of the floor system were established by the arithmetic transformations (segmentation and adjacency) schematized in Figure 27a.

\subsection{Concentration of masses}

In studies whose premise is an overall response of the building governed by the in-plane behavior of the walls, the masses are concentrated on nodes located on the walls. In this study, the nodal masses of the PB were located at the nodes of intersection of the piers' axes with the floors' planes. The piers and spandrels contribute to these nodal masses, as well as the floor diaphragms with their respective vertical load. The tributary masses of the piers and spandrels were calculated from the areas generated by the crossing of the lines passing through the halves of the stories and through the halves of the openings (Figure 28a). For the masses of the floor diaphragms, we initially adopted the scheme proposed by Kim and White (2004): a grid of nine rectangular areas with strips of a quarter of the length of the spans from their four edges (Figure 28b). From this scheme, the tributary masses of the floor system were distributed to the nodal masses located at the perimeter piers. The masses corresponding to the eight peripheral areas and those corresponding to the central area contributed to the nearest nodal mass. If this maximum closeness is verified in terms of equidistance (or quasiequidistance), the tributary mass is distributed equally between the equidistant nodal masses (Figure 28b).

\subsection{Boundary Conditions of the Piers}


In URM buildings, the stiffness and strength of the spandrels can vary significantly, which generates different levels of coupling between piers. Several authors (Tomazevic 1999; Lang 2002; Petry and Beyer 2014; Lagomarsino and Cattari 2015b) distinguish three cases: weak coupling, strong coupling and intermediate coupling. In the weak coupling case, the horizontal elements impose only equal displacements on the walls of each story without practically transferring shear forces or bending moments. Therefore, this constitutes a subtypology of the URM buildings whose model does not fit the EF approach (moment profiles of masonry walls exhibiting shear spans greater than $1.0 \mathrm{H}$, that is, $\psi^{\prime}>1.0$ ). Thus, this study covers the field of URM buildings with strong and intermediate coupling, in which the piers present boundary conditions (degrees of restraint against rotation of their ends) ranging from fixed-fixed BCP (shear span $\mathrm{H}_{0}=0.5 \mathrm{H} ; \psi^{\prime}=0.5$ ) to cantilever BCP (shear span $\mathrm{H}_{0}=1.0 \mathrm{H} ; \psi^{\prime}$ $=1.0)$ as limit conditions.

The BCP affect the lateral stiffnesses and the strength capacities of the piers. The model proposed for the PB cannot evaluate the BCP and rigorously incorporate their influence on the FDRs of such members. To overcome this limitation, as with the proposed EF-model, three pushover analyses were performed under the three BCP considered in Section 3: fixed-fixed $\left(\psi^{\prime}=0.5\right)$, intermediate $\left(\psi^{\prime}=0.75\right)$ and cantilever $\left(\psi^{\prime}=1.0\right)$. For the intermediate case, the lateral stiffnesses and the effective length factors of the piers were evaluated as the average of the corresponding values associated with the cantilever and fixed-fixed BCP (e.g. $\psi^{\prime}=0.75$ ). The objectives of the three pushover analyses were to establish the influence of BCP on the characteristics of the curves obtained and to identify among the three BCP examined what would be the most representative of the real BCP of the PB. The pushover curves obtained with the Tremuri program were used as a benchmark. Thus, Figures 29a and 29b show, for each orthogonal direction of the PB, the three pushover curves obtained with Ruaumoko PBCA, PB-I and PB-FF, namely: PB with cantilever, intermediate and fixed-fixed BCP, 
respectively, and the pushover curve obtained with Tremuri: PB-TR. Two assumptions were adopted in both Ruaumoko and Tremuri: 1) a lateral load proportional to the first mode of vibration, and 2) the node of the roof floor closest to its center of mass functions as displacements control node. Henceforth, these two assumptions were maintained for all pushover analyses developed with Ruaumoko on the PB. Furthermore, since the pushover analysis in Ruaumoko enables curves with virtually zero residual strength, it was decided to interrupt them in the penultimate or antepenultimate analysis step. This decision was maintained for all subsequent pushover analyzes on PB.

Thus, the pushover curves obtained with Ruaumoko (Figures 29a and 29b) showed that the increase in value of the BCP (passage from the fixed-fixed to the cantilever condition) entails decreases in the elastic stiffness, base shear capacity and displacement capacity. This last tendency, which refers to displacement capacity, contrasts to that presented at wall scale (Figure 18b). This would explain the dominant influence on the displacement capacity of the flexible floor and, in the case of the transverse direction of the $\mathrm{PB}$, the fact that the node on which the displacement is controlled is on one of the central walls, which are the weakest in that direction. The increases in base shear capacity of the pushover curves of the PB are approximately $250 \mathrm{kN}$ in the case of curves corresponding to the transversal direction (from PB-CA to PB-I: 13\%, and from PB-I to PB-FF: 11\%; see Figure 29a), and $500 \mathrm{kN}$ in the case of curves corresponding to the longitudinal direction (from PB-CA to PB-I: 20\% and from PB-I to PB-FF: 17\%; see Figure 29b). However, when this set of three curves was compared with the reference curve PB-TR, it was verified in the two orthogonal directions of the PB that greater agreement was reached with the PB-I curve. In particular, with respect to the pushover curves corresponding to the transverse direction of the building (lateral load parallel to the transverse direction of the PB), the following is observed: PB-I and PB-TR practically coincide in terms of base shear capacity, the elastic stiffness of PB-I is approximately $15 \%$ 
greater than that of PB-TR, and the displacement capacity (measured at the point where 20\% of strength decay from $0.9 \mathrm{Vu}$ is verified) of PB-I is greater than that of PB-TR, by approximately $18 \%$. This greater displacement capacity exhibited by PB-I is explained by the assumption of greater failure drifts for the piers (see Figures 8a and 8b) compared with those assumed by Tremuri (shear failure drift: $0.4 \%$, flexural failure drift: $0.6 \%$ ). Therefore, considering the differences between the two programs (Section 4.4.1), the discrepancies between the two pushover curves are considered reasonable and acceptable.

Thus, since the intermediate BCP (under the terms set) represents the best approximation to the real BCP of the PB, the study of the effect of stiffening of the floor system will be carried out on the model corresponding to PB-I, which will constitute the first unstiffened case of this study and to which we will refer henceforth with the acronym PB-US. Thus, in the first instance, regarding PB-US, there was very good agreement between the values of the basic modal parameters of the first modes of vibration reached with the proposed 3D model (Ruaumoko) and with the EF-model proposed by Tremuri (see Table 9).

\section{INFLUENCE OF THE STIFFNESS OF THE FLOOR SYSTEM ON THE SEISMIC BEHAVIOR OF THE PROTOTYPE BUILDING}

\subsection{First application: Prototype building with SBBV-floor system}

\subsubsection{Characteristics of the stiffened diaphragms}

To examine the influence of the stiffening of the floor system, the PB-US case was stiffened with techniques used in practice whose seismic performance has been studied. Figure 30 shows the variants that have been considered: 1) stiffened with diagonal bracing, PB-S1 (Figure 30a), and 2) stiffened with a concrete topping, PB-S2 (Figure 30b). The arithmetic of the assignment of shear stiffnesses to the floor springs means that the different techniques of stiffening interventions could be considered by applying a stiffening factor (shear stiffness of stiffened variant/shear stiffness of unstiffened case) to the stiffnesses of the PB-US case. The 
stiffening factors for the PB-S1 and PB-S2 variants were determined from the shear stiffnesses obtained in the framework of an experimental campaign in which the test setup and the size of the specimen were maintained (Mahdizadeh et al. 2012; Shakib et al. 2014). Table 10 presents the stiffening factors of the variants, which were applied to each diaphragm of the floor system on the springs of its long edge $\left(L_{1}\right)$ and on the springs of its short edge $\left(L_{2}\right)$. Furthermore, it was considered relevant to include the variants with a fully rigid floor, PB-RF, and with a very flexible floor, PB-VF, which were obtained by applying stiffening factors of 500 and 0.7, respectively, to the shear stiffnesses (or to $G_{e q}$ ) of the FDMs corresponding to the unstiffened case PB-US (SBBV-floor). From these referential stiffnesses, which represent a flexible floor, a factor of 500 would represent an infinitely rigid floor (hereinafter named "fully rigid floor"), and a factor of 0.7 , a very flexible floor (e.g. a weak wooden floor). The $G_{e q}$ values adopted in the parametric analysis of Brignola et al. (2009) served as reference for the assumption of these factors.

\subsubsection{Effects on the pushover curves}

Figure 31 shows the pushover curves of the four stiffened variants associated with PB-US (from the PB-VF case to the PB-RF case; lateral load parallel to the transverse direction of the PB), revealing a double effect of the stiffening of the floor system: an increase in the base shear capacity and a decrease in the displacement capacity. The significant differences between the PB-VF and the PB-US curves and between PB-US and PB-S1 (or PB-S2) reveal greater sensitivity to variation in the shear stiffness of the floor diaphragms (especially in terms of displacement capacity) than the PB-variants exhibit in the lower range of stiffnesses. In contrast, in the range of the stiffened variants PB-S1 and PB-S2, with stiffening factors between 2 and 5, the differences in both base shear and displacement capacities are noticeably smaller. Hence, the scope of analysis was reduced to the three variants: PB-US, PB-S2 and PB-RF. Figure 32 illustrates the difference, in terms of pushover curves, of the effect of 
stiffening the floor system, depending on whether the lateral load acts parallel to the transverse or longitudinal direction of the PB. In both loading directions, an increase in the base shear occurs. However, the displacement capacity shows contrary tendencies, which increase when the lateral load acts parallel to the longitudinal direction. This behavior is explained by the small number of bays involved and the rigid wall role played by the central core staircase, which inhibits the flexible floor effect and delegates the lateral deformability of the building exclusively to the piers.

\subsubsection{Effects on the modal properties and the deformed shape}

Periods and modal effective masses have been grouped in Tables 11 and 12. Table 11 presents a description of the first four modal forms verified under a rigid floor assumption (PB-RF), and Table 12 shows the first three modes corresponding to the unstiffened and stiffened variants: PB-US and PB-S2. $\mathrm{M}_{\mathrm{e}} \mathrm{X}$ and $\mathrm{Me}_{\mathrm{e}} \mathrm{Z}$ represent the effective masses in the transverse and longitudinal directions of the $\mathrm{PB}$, respectively; $\mathrm{Me}_{\mathrm{e}} \mathrm{X}$ (ac.) and $\mathrm{M}_{\mathrm{e}} \mathrm{Z}(\mathrm{ac}$.), the accumulated effective masses; and \% MX and \% MZ, the percentages of accumulated effective mass. The mode indicated with an asterisk corresponds to the first torsional mode (lateral torsional mode). Since their participation was very small, effective rotational masses were not detailed. From the analysis of Tables 11 and 12, it should be noted that the participation of the first modes of translational vibration were clearly predominant, which means that the seismic behavior of the PB would be governed by the first mode in each orthogonal direction. In the case of the PB-RF variant (Table 11), the first four modes activated almost the entire mass of the building in the two orthogonal directions (\%MX $=95 \%, \% \mathrm{MZ}=93 \%)$. In addition, the fact that the first four modes were translational is indicative of the high degree of regularity in the plan and elevation of the PB. This had already been verified by the uniform distribution of the nodal masses (see Figure 28b). Floor system stiffening led to slight stiffening of the PB: the period of the first mode varied from $\mathrm{T} 1=0.566 \mathrm{~s}$ (PB-US case) to $\mathrm{T} 1=0.523 \mathrm{~s}$ (PB-RF variant) 
and T1=0.54s for the stiffened variant PB-S2 (Table 12). Greater floor system stiffness meant greater participation percentages of effective mass. This is particularly evident in the case of the fully rigid floor, where the participation of the first three modes accumulated $95 \%$ of the total mass. The high percentages of the effective modal mass of the first modes (in each orthogonal direction) that were verified for the PB corroborate the modal analysis results of other studies that addressed the seismic behavior of URM buildings in the EixampleBarcelona district with similar geometric and architectural characteristics. Bonett (2003), Moreno and Bairan (2011), Pujades et al. (2012) and Gonzalez-Drigo et al. (2017) used Tremuri modal analysis to determine a \%MX (transverse direction) of between $85 \%$ and $90 \%$ and a \%MZ (longitudinal direction) of between $75 \%$ and $80 \%$. Considering these results, somewhat higher percentages of the effective modal mass of the first modes were expected for the PB. Notably, Tremuri's lumped mass model differs from the model proposed here (Section 5.3), since it concentrates the nodal masses at the points of intersection between orthogonal walls and floors.

As regards the displacement capacity of the $\mathrm{PB}$, it is well known that greater flexibility of the floor system entails greater independence of behavior of the walls and, therefore, considerable displacements in weak walls (with less lateral stiffness). In the case of the PB, the flexible diaphragm effect is particularly pronounced when the lateral load acts according to its transverse direction because of the weakness of the inner walls, which is progressive as they approach the central axis of the building from the façade walls. This is evidenced with the evolution of the deformed shape of the floors during the pushover analysis (Figure 33). The deformed shapes of each floor were delineated by joining the displaced positions of the intersecting nodes between the transverse walls and the lateral walls at the level of each of the floors. Figure 33 shows the control points considered on the pushover curves of the PB-US, PB-S2 and PB-RF variants (with a lateral load parallel to the transverse direction of the PB), 
and the deformed shapes (which are exaggerated, for comparison purposes, using an amplification factor) of the PB's floors associated with these points.

Figures 33a and 33b show the effect of stiffening on the deformed shape of the floors of the PB-US case, in terms of reduction and homogenization of displacements. The displacement Dmax, verified at the beginning of the drop in strength, was reduced by $35 \%$ from $56 \mathrm{~mm}$ to $35.5 \mathrm{~mm}$. The shear displacements of the floor diaphragms, which cause greater displacements in the central bay due to the weakness of the central transverse walls, decreased significantly with stiffening, until they became null with the PB-RF variant (Figure 33c).

\subsection{Second application: Prototype building with timber floor system}

\subsubsection{Characteristics of the timber floor and its stiffened variants}

To enrich the conclusions about the effect of the floor system's flexibility, we considered a second case of the Building Prototype with a timber floor, which is also representative of the pre-modernist period in the Eixample-Barcelona (1860-1880). Taking into account the most common form of this case (in the Eixample-Barcelona), the first two floors were assumed to be of SBBV and the remaining four floors of timber. As with the first case (SBBV-floor), three variants were analyzed: the (original) unstiffened case and two stiffened variants. Figure 34a shows the floor components of the unstiffened case (hereafter PB-TF-US) together with their load values. Figures 34b and 34c show the typological characteristics of the stiffened variants considered: 1) with double orthogonal sheathing: PB-TF-S1 and 2) with diagonal strips of carbon fiber reinforced plastic (CFRP): PB-TF-S2. It should be noted that the stiffened variant PB-TF-S1 constitutes a variant in the Eixample-Barcelona, which is less common than the unstiffened case PB-TF-US. Finally, for the PB-TF-US basic case, the SBBV-floors are the same as those of the unstiffened case PB-US, while for the stiffened 
variants (PB-TF-S1 and PB-TF-S2), the SBBV-floors are the same as those of the PB-S1 variant (stiffened with diagonal bracing).

The case PB-TF-US has the following typological details: pine beams of $5 \times 8$ inches with spacing of $50 \mathrm{~cm}$; board thickness: $3 \mathrm{~cm}$. These dimensions are typical of this type of floor in the Eixample-Barcelona (Paricio 2008; Gonzalez-Drigo et al. 2015). Both the lengths of spans and the non-existence of tie beams are conserved for the above variants (PB-TF-US, PB-TFS1 and PB-TF-S2). Therefore, the assumption of simple shear behavior of the floor diaphragm was also maintained. Hence, experimental and analytical studies evaluating the shear stiffness of the diaphragm floor have focused on the shear stiffness of the diaphragm with the lateral load parallel to the beams (Brignola et al. 2009; Valluzzi et al. 2010; Branco et al. 2013). The lack of studies considering lateral loading orthogonal to the beams was overcome by adopting the formulation proposed in Gattesco and Macorini (2014), based on principles of work. This formulation, deduced for simple timber floors, was also used here for the stiffened variants.

Considering the lateral load parallel to the beams, the shear stiffness corresponding to the PBTB-US case was based mainly on an analytical study by Brignola et al. (2009), from which a $\mathrm{G}_{\text {eq }}$ of $20 \mathrm{MPa}$ was assumed. The shear stiffnesses corresponding to stiffened variants were based on the experimental studies of Valluzzi et al. (2010) and Branco et al. (2013) for the PB-TF-S1 variant, and Gattesco and Macorini (2014) for the PB-TF-S2 variant. The experimental shear stiffnesses assumed for the stiffened variants were such that they yielded stiffening factors of 4 and of 40 for the PB-TF-S1 and PB-TF-S2 variants, respectively. In Jiménez-Pacheco (2016), a broader discussion of these assumptions is developed.

Regarding the $\mathrm{G}_{\text {eq }}$ (unstiffened case), the study by Brignola et al. (2009) was carried out in two phases. The first consisted of deducing a formula for $\mathrm{G}_{\mathrm{eq}}$, which was based on the lateral load condition illustrated in Figure 35a and on the consideration of the three contributions to 
the deformed shape shown in Figures 35c, 35d and 35e. From the formula of $\mathrm{G}_{\text {eq }}$, the second phase consisted of a parametric study, in which the thickness of the boarding, the separation between beams and the diameter of the nails were used as parameters.

\subsubsection{Effects of the stiffening of the floor system: comparison with the first application}

Thus, from the two orthogonal shear stiffnesses of each macro-element, the final values of shear stiffness of the floor springs obeyed the arithmetic process described in 5.2 .2 and illustrated in Figure 27a. As for the dynamic behavior of these PB-variants with timber floor, in Jiménez-Pacheco (2016), several modal analysis results are presented. Here we will highlight that the PB-TF-US case was slightly more flexible (T1=0.57s) than the PB-US case $(\mathrm{T} 1=0.56 \mathrm{~s})$. However, regarding the behavior under a lateral load, in Figure 36 the pushover curves of the PB-TF variants are presented: PB-TF-US, PB-TF-S1 and PB-TF-S2 superimposed on the curves of the PB-variants with an SBBV-floor, PB-US, PB-S2 and the limit case PB-RF. For comparative purposes, two conditions are relevant: the distribution of the lateral load was assumed, in all cases, to be proportional to the first mode of vibration and the vertical load of $350 \mathrm{~kg} / \mathrm{m}^{2}\left(3.43 \mathrm{kN} / \mathrm{m}^{2}\right)$ on the floors coincides in all cases (both SBBVfloor variants and timber floor variants). This ensures that the effect captured in the pushover curves of Figure 36 is that of the flexibility of the floor system. In addition, it should be noted that the shear stiffnesses of the floor springs of the PB-TF-US case, compared to the original PB-US case, were between $10 \%$ and $20 \%$ lower (the timber floor was around $15 \%$ more flexible than the SBBV-floor).

Under the aforementioned conditions, the two most remarkable aspects of the pushover curves in Figure 36 are: the considerable approximation to the fully rigid floor limit case PBRF that involved stiffening of the unstiffened cases (curves PB-TF-S1, PB-S2 and PB-TF-S2) and the notably greater sensitivity in the range of flexible floors (PB-TF-US and PB-US). This sensitivity (under variations of shear stiffness) is evidenced especially in terms of the 
displacement. Thus, the flexibilization of around 15\% that involved changing the SBBV-floor to the timber floor led to a $40 \%$ increase in displacement capacity (displacement at the strength drop point). The effect in terms of base shear capacity was more moderate: around a $10 \%$ decrease. In contrast, in the range of stiffened floors with stiffening factors between 2 and 5 (PB-TF-S1 and PB-S2), the variations exhibited by the pushover curves are very small (PB-TF-S1 and PB-S2 curves). In the general scope of the stiffened floors, the moderate difference between the curves of the stiffened variants PB-TF-S1 and PB-TF-S2 (Figure 36) obeyed a significant variation in the floor stiffness: the stiffening factor of the variant PB-TFS1 was 4, while that of the variant PB-TF-S2 was 40.

Finally, it was considered pertinent to show the effect of the stiffening of the floor system on the lateral displacement profiles of two walls of the PB. The vertical irregularity that supposes not having the same floor system in the entire height of the building gives rise to a significant difference of behavior, in terms of lateral displacement profiles, with respect to the first application on the PB. Herein, we will briefly confront the (unstiffened) basic cases. Thus, Figures 37c and 37d show the lateral displacement profiles corresponding to the walls located on axes 6 and 3 (Figure 1b), that is, the front façade wall (Figure 26a) and the strongest central wall (the same as in Figure 26b, but without windows along the central vertical axis). Three profiles are presented for each wall corresponding to the unstiffened case PB-TF-US, the stiffened variant PB-TF-S1 (see Figure 34b), and the fully rigid variant PB-RF. In relation to the pushover analysis, the profiles were established just before the sustained degradation of strength (Figures 37a and 37b). Regarding the influence of the floor system stiffening, the most evident is that the central wall, much weaker than the façade wall, is much more sensitive to the variations of stiffness of the floor system (Figures 37c and 37d). Beyond the greater displacements that exhibit the displacement profiles, two issues about the central wall deserve to be highlighted. First, regarding the PB-TF-US case, the noticeable increase in 
interstory drift between the third and fourth floors (black-line profile in Figure 37d) constitutes a soft-story problem limited to the central part of the building. This is because having the first two floors of SBBV and the subsequent ones of timber means changing from flexible floor to an even more flexible floor. Second, the stiffening of the PB (PB-TF-S1 case), although it inhibits the soft-story problem on the third floor, it activates a soft-storey problem on the first floor derived from the decrease in wall thickness from $20 \mathrm{~cm}$ to $15 \mathrm{~cm}$ (see Table 1). In this regard, it is worth noting that the lateral displacement profile of the stiffened case PB-TF-S1 is similar, in terms of shape, to that of the unstiffened case PB-US, showing a decrease in displacements between 25 and 30\%. Thus, the results show that the response of high URM buildings with flexible floors, in terms of lateral displacement profile, is very sensitive to vertical irregularities (e.g. partial change or stiffening of the floor system, decrease in wall thickness). As a corrective measure, the stiffening of the floor system must be handled very carefully, since at the same time it inhibits a certain undesirable effect, it can activate another (compare profiles PF-TF-US and PB-TF-S1). In this sense, the PB-TF-S3 case was established as a local overstiffening of the second floor on the PB-TF-S1 case (SBBV-floor stiffened with diagonal bracing; see Table 10) obtained with the application of a stiffening factor of 5 in the shear stiffnesses of the springs corresponding to the SBBV-floor. Although this intervention corrects to some extent the problem of soft floor on the second floor, it should be noted that the increase of the stiffening factor to 10 (simulation not included in Figure 37d) does not correct it, but rather displaces it to the third floor.

\section{DISCUSSION OF RESULTS AND CONCLUSIONS}

\subsection{Contextualization of the results with those obtained in other studies}

Recent research about the influence of the floor system's flexibility on the seismic behavior of URM buildings has focused on low-rise buildings, with an orientation towards seismic design 
(Giongo 2013; Nakamura et al. 2017b; Kollerathu and Menon 2017). This study focuses on high-rise URM buildings and is aimed at seismic evaluation and strengthening of residential buildings. Previous studies (Moon and Lee 1994; Barron and Hueste 2004; Sadashiva et al. 2012) based on parametric analyses of idealized buildings came to the important conclusion that the effects of the floor system's flexibility decrease with an increment in story number and span number. In addition, Moon and Lee (1994) compared framed systems with systems that had shear walls instead of exterior frames. They concluded that flexibility effects are more accentuated in the latter. This observation is relevant, since in URM residential buildings (e.g. the PB), façade walls are commonly thicker than interior walls and are, therefore, considerably more rigid.

Thus, the study by Moon and Lee (1994) constitutes a good framework for discussing the results obtained here and in recent papers (Giongo 2013; Nakamura et al. 2017b; Kollerathu and Menon 2017). Since the buildings considered in those studies share with the PB the characteristics of regular geometry and uniform distribution of the elements of the lateral loads resistant system, the results and conclusions concern buildings with regular plans (in particular, URM buildings). The approach to the problem differs: while the flexibility of the floor diaphragm was handled here in terms of stiffening, taking into account three cases (unstiffened case, stiffened variant and variant with fully rigid floor), the approach in the reference works was one of flexibilization in two cases (flexible floor and fully rigid floor). Table 13 summarizes the characteristics of the buildings that were analyzed and the types of analyses carried out in the studies considered.

In the next section, the results will be compared. With this aim, Table 14 shows the impact, in percentage terms, of the variations caused by floor system stiffening on the three seismic responses that were considered. In particular, columns PB-S2 and PB-RF refer to the effects on the basic case PB-US caused by such stiffening interventions (Figure 32). 
Firstly, the results of Moon and Lee (1994) shown in Table 14 are those reported for a 5-story and 5-bay building, with shear walls instead of end frames, the closest in typological and geometric terms to the PB. For this reason, the variations in the three responses studied in the work of Moon and Lee (1994) show the same tendency as in the two cases examined here: PB-S2 and PB-RF. In this reference work, the floor subject to stiffening corresponds to a stiffened variant (stiff floor) rather than to an unstiffened case (flexible floor), which explains the greater percentages of variation obtained herein as a product of the stiffening to fully rigid floor (see column PB-RF in Table 14).

Regarding the values in Table 14 for variations in base shear capacity and fundamental period, the trends are maintained in all studies. In addition, the sizes of such variations are within the ranges expected according to the papers by Moon and Lee (1994) and Sadashiva et al. (2012). In contrast, the displacement capacity (maximum displacement of the walls) is sensitive with respect to the variation in the stiffness of the floor system. The trend even changes for one and two-story buildings. Factors that are determining in this sensitivity are the varying stiffness of the exterior and interior walls, the number of stories and the number of bays. As a corroboration, in Moon and Lee (1994) a slight change in tendency in the displacement capacity can be observed when the effect of the stiffening is compared between the building with shear walls of 5-stories and 5-bays and the framed building of 2-stories and 3-bays (the smallest). For URM buildings with more flexible floors of one or two stories and one or two bays, a much more significant change of tendency in the variation of the displacement capacity should be expected: the results of Giongo (2013), Nakamura et al. (2017b) and Kollerathu and Menon (2017) support this.

\subsection{Conclusions and future research}


Under the assumption of a global failure governed by in-plane failure mechanisms of the walls, a model to perform nonlinear static analysis of URM buildings with non-rigid floors was implemented in this study. Within the EF-approach, such a model consisted of an assembly of spring-type macro-elements for walls and floor diaphragms. The proposed EFmodel was validated using as a benchmark the results of three widely recognized studies in the literature. The FDM, characterized by shear stiffnesses in the two orthogonal directions and implemented in the floor system, can easily capture the orthogonal behavior of unidirectional floor systems that are typical in a traditional URM. This macro-element, which is conceived to capture the shear component in the deformed shape of the floor diaphragms, seems to be appropriate for unidirectional floors without tie-beams that are not large and have an aspect ratio not too far from unity (these floor diaphragm features are common in URM buildings in Mediterranean countries and, in particular, in URM buildings in the EixampleBarcelona district).

The proposed 3D model was applied to a typical building of the Eixample-Barcelona district (PB): high, elongated and with a high degree of symmetry in plan. The adjustment of this model in terms of the BCP led to the conclusion that intermediate (or semi-restrained) BCP is the most representative for the PB. As for the basic objective, stiffening the floor system of the PB entailed a slight stiffening of the building, reflected in slight decreases in the fundamental period, slight to moderate increases in base shear capacity and significant decreases in displacement capacity. This more pronounced effect on the displacement capacity was due the greatest stiffness of the outer walls and progressive weakness towards the inner walls of the PB. From a literature review, these effects of floor system stiffening are expected to intensify with a reduction in the number of stories and bays, changing even the trend in the case of the displacement capacity. On the other hand, the lateral displacement profiles of the PB becomes sensitive in the presence of flexible floor systems. Reductions in 
wall thicknesses and changes in floor systems along the height of the building lead to significant variations in interstory drifts. As a corrective measure, the stiffening of the floor system must be handled very carefully, since at the same time it inhibits a certain undesirable effect, it can activate another.

Thus, for high URM buildings with a considerable degree of symmetry, the outcomes of global seismic behavior obtained here can serve as a reference for seismic assessment studies, particularly for those interested in the effect of stiffening the floor system as a vulnerability reduction strategy. In the context of the territorial scale of seismic vulnerability studies, these outcomes could provide arguments for a reviewing or extending existing taxonomies and fragility curves for URM buildings.

With a view to improving the proposed EF-model, among the short-term research lines are, on the one hand, a more rigorous validation of the proposed FDM, task that will probably lead to a more refined macro-element, and, on the other hand, the consideration of the interactions with the axial force in the strength capacities of the members. As research lines of greater scope, parametric studies that take into account variables influencing the BCP (e.g. regularity, location, and size of openings) and provide criteria for its assignment would be very useful for simplified models such as the one proposed here. Furthermore, to establish the limits of applicability of the proposed model, two issues must be addressed. First, in relation to regular/symmetrical buildings, it is important to identify the factors that have a greater incidence on the predominant deformed shape of the existing flexible floor systems and, once identified, to determine threshold values demarcating the two types of floor system response: dominated by the shear component and dominated by the bending component. Second, in relation to non-regular/asymmetrical buildings, a limit value of shear stiffness of the floor diaphragm for which it is acceptable to neglect the torsional effects should be established. 


\section{ACKNOWLEDGMENTS}

We thank Lucille Banham for her assistance in the preparation of the English manuscript.

This research was partially funded by the Ministry of Economy and Competitiveness (MINECO) of the Spanish Government and by the European Regional Development Fund (ERDF) of the European Union (EU) through projects referenced as: CGL2015-65913-P (MINECO/ERDF, EU) and EFA158/16/POCRISC (INTERREG/POCTEFA. EU). Juan Jiménez-Pacheco, sponsored by the University of Cuenca, obtained a scholarship from the Ministry of Higher Education, Science and Technology (SENESCYT), Government of Ecuador, for doctoral studies in the Earthquake Engineering program of the UPC-Barcelona Tech. The main results presented and discussed in this work correspond to his doctoral thesis. Some of these results have been refined and complemented as part of a research project “Capacidad sismorresistente y modos de falla de edificaciones de mampostería no reforzada típicas del Centro Histórico de Cuenca” (Seismic-resistant capacity and failure modes of nonreinforced masonry buildings typical of the Historic Center of Cuenca), carried out by the Seismic Network of the Austro (Red Sísmica del Austro), with the sponsorship and funding of the Research Direction of University of Cuenca (Dirección de Investigación de la Universidad de Cuenca).

\section{REFERENCES}

Ahmed, I. M., and K. D. Tsavdaridis. 2019. The evolution of composite flooring systems: applications, testing, modelling and eurocode design approaches. Journal of Constructional Steel Research 155: 286-300. Elsevier. doi:10.1016/j.jcsr.2019.01.007.

Akhaveissy, A. H., and M. Abbassi. 2014. Pushover analysis of unreinforced masonry structures by fiber finite element method. Journal of Research in Civil and Environmental Engineering 2 (03):96119.

Amadio, C., G. Rinaldin, and L. Macorini. 2011. An equivalent frame model for non-linear analysis of unreinforced masonry buildings under in-plane cyclic loading. Proceedings of the 14th National Conference of Earthquake Engineering, Bari, Italy.

ASCE/SEI 41-13. 2014. Seismic Evaluation and Retrofit of Existing Buildings. Reston, VA: American Society of Civil Engineers: Structural Engineering Institute. 
ASCE/SEI 41-17. 2017. Seismic Evaluation and Retrofit of Existing Buildings. Reston, VA: American Society of Civil Engineers: Structural Engineering Institute.

ASCE/SEI 7-10. 2010. Minimum design loads for buildings and other structures. Reston, VA: American Society of Civil Engineers: Structural Engineering Institute.

Azizi-Bondarabadi, H., N. Mendes, and P. B. Lourenço. 2019. Higher Mode Effects in Pushover Analysis of Irregular Masonry Buildings. Journal of Earthquake Engineering: 1-35. Taylor \& Francis. doi:10.1080/13632469.2019.1579770.

Bahar, S., A. Benanane, A. Belarbi. 2019. The influence of deformability of horizontal diaphragms in the distribution of seismic loads to bracing elements in rectangular buildings. Journal of Materials and Engineering Structures 6:105-18. Mouloud Mammeri University of Tizi-Ouzou.

Barron, J.M., and M. B. D. Hueste. 2004. Diaphragm effects in rectangular reinforced concrete buildings. ACI Structural Journal 3:89-98. American Concrete Institute (ACI).

Bazarchi, E., Y. Hosseinzadeh, and P. Panjebashi Aghdam. 2018. Investigating the in-plane flexibility of steel-deck composite floors in steel structures. International Journal of Structural Integrity 9 (5):705-20. Emerald Group Publishing. doi:10.1108/ijsi-02-2018-0010.

BHRC. 2015. Iranian code of practice for seismic resistant design of buildings (Standard No. 2800). Fourth Revision. Tehran, Iran: Building and Housing Research Center, Iran (in Persian).

Bonett, R. 2003. Vulnerabilidad y riesgo sísmico de edificios: Aplicación a entornos urbanos en zonas de amenaza alta y moderada. PhD Thesis. Universidad Politécnica de Cataluña, Barcelona.

Bothara, J. K., R. P. Dhakal, and J. B. Mander. 2009. Seismic performance of an unreinforced masonry building: An experimental investigation. Earthquake Engineering \& Structural Dynamics 39:45-68. Wiley-Blackwell. doi:10.1002/eqe.932.

Branco, J. M., M. Kekeliak, and P. B. Lourenço. 2015. In-plane stiffness of timber floors strengthened with CLT. European Journal of Wood and Wood Products 73 (3):313-323. Springer. doi:10.1007/s00107-015-0892-2.

Brando, G., De Matteis, G., \& Spacone, E. 2017. Predictive model for the seismic vulnerability assessment of small historic centres: Application to the inner Abruzzi Region in Italy. Engineering Structures, 153:81-96. doi:10.1016/j.engstruct.2017.10.013.

Brignola, A. 2009. Evaluation of the in-plane stiffness of timber floors for the performance-based retrofit of URM buildings. PhD Thesis. University of Genoa, Italy.

Brignola A., S. Pampanin, and S. Podestà. 2009. Evaluation and control of the in-plane stiffness of timber floors for the performance-based retrofit of URM buildings. Bull New Zealand Society for Earthquake Engineering 42:204-21. New Zealand Society for Earthquake Engineering (NZSEE).

Brignola, A., S. Pampanin, and S. Podestà. 2012. Experimental Evaluation of the In-plane stiffness of timber diaphragms. Earthquake Spectra 28 (4):1687-709. Instituto de Investigación de Ingeniería de Terremotos (EERI). doi:10.1193/1.4000088.

Calderini, C., Cattari, S., Lagomarsino, S. 2009. In plane seismic response of unreinforced masonry walls: comparison between detailed and equivalent frame models. In: M. Papadrakakis, N. Lagaros, M. Fragiadakis (eds). Proceedings of COMPDYN 2009: 2nd International Conference on Computational Methods in Structural Dynamics and Earthquake Engineering, Rhodes, Greece.

Bucchi, F., Arangio, S., Bontempi, F. 2013. Seismic Assessment of an Historical Masonry Building using Nonlinear Static Analysis. In: B.H.V. Topping and P. Iványi, (Editors): Proceedings of the Fourteenth International Conference on Civil, Structural and Environmental Engineering Computing, Stirlingshire, UK.

Calderini, C., S. Cattari, A. S. Degli, S. Lagomarsino, D. Ottonelli, M. Rossi. 2012. Modelling strategies for seismic global response and local mechanisms. In Deliverable D26, WP No5, 
PERPETUATE Project (FP7). European Research Project on the Seismic Protection of Cultural Heritage.

Caliò, I., M. Marletta, and B. Pantò. 2012. A new discrete element model for the evaluation of the seismic behaviour of unreinforced masonry buildings. Engineering Structures 40:327-38. Elsevier. doi:10.1016/j.engstruct.2012.02.039.

Calvi, G.M., and G. Magenes. 1994. Experimental Research on Response of URM building systems. Technical Report NCEER-94-0021. In Proceedings of U.S.-Italy Workshop on Guidelines for Seismic Evaluation and Rehabilitation of Unreinforced Masonry Buildings 21 (3):41-57.

Carr, A. 2007a. Theory. Ruaumoko manuals, Volume 1. University of Canterbury, Christchurch, New Zealand.

Carr, A. 2007b. User Manual for the 2-Dimensional version - Ruaumoko 2D. Ruaumoko manuals, Volume 2. University of Canterbury, Christchurch, New Zealand.

Carr, A. 2007c. User Manual for the 3-Dimensional version - Ruaumoko 3D. Ruaumoko manuals, Volume 3. University of Canterbury, Christchurch, New Zealand.

Carr, A. 2007d. Appendices. Ruaumoko manuals, Volume 5. University of Canterbury, Christchurch, New Zealand.

Cattari, S., Beyer, K. 2015. Influence of spandrel modelling on the seismic of existing masonry buildings. In: Proceedings of the Tenth Pacific Conference on Earthquake Engineering Building an Earthquake-Resilient Pacific, Sydney, Australia.

Cattari, S., S. Lagomarsino, and S. Marino. 2015. Reliability of nonlinear static analysis in case of irregular URM buildings with flexible diaphragms. Proceedings of the Conference SECED: Earthquaque Risk and Engineering towards a Resilient World, Cambridge, UK.

Cattari, S., S. Lagomarsino, D. D’Ayala, V. Novelli, V. Bosiljkov. 2012. Correlation of performance levels and damage states for types of buildings. In: Deliverable D17, WP No6, PERPETUATE Project (FP7), European Research Project on the Seismic Protection of Cultural Heritage.

Chen, S.Y., F. Moon, and T. Yi. 2008. A macro-element for the nonlinear analysis of in plane unreinforced masonry piers. Engineering Structures 30(8):2242-52.

Diana, L., A. Manno, and P. Lestuzzi. 2019. Seismic displacement demand prediction in non-linear domain: Optimization of the N2 method. Earthquake Engineering and Engineering Vibration 18 (1):141-58. Springer. doi:10.1007/s11803-019-0495-8.

Dolatshahi, K. M., M. T. Nikoukalam, and K. Beyer. 2018. Numerical study on factors that influence the in-plane drift capacity of unreinforced masonry walls. Earthquake Engineering \& Structural Dynamics 47(6):1440-59. Wiley-Blackwell. doi:10.1002/eqe.3024.

Dolce, M. 1991. Schematizzazione e modellazione degli edifici in muratura soggetti ad azioni sismiche (Drafting and modeling of masonry buildings subjected to seismic actions) [in Italian], L’Industria Delle Costr. 25:44-57.

Eivani, H., A. S. Moghadam, A. Aziminejad, and M. Nekooei. 2018. Seismic Response of PlanAsymmetric Structures with Diaphragm Flexibility. Shock and Vibration:1-18. Hindawi Publishing Corp. doi:10.1155/2018/4149212.

Esposito, R., F. Messali, G. J. P. Ravenshorst, H. R. Schipper, and J. G. Rots. 2019. Seismic assessment of a lab-tested two-storey unreinforced masonry Dutch terraced house. Bulletin of Earthquake Engineering. 17 (8):4601-23. Springer. doi:10.1007/s10518-019-00572-w.

FEMA 273. 1997. NEHRP guidelines for the seismic rehabilitation of buildings. Washington, D.C.: Federal Emergency Management Agency. 
FEMA 306. 1998. Evaluation of earthquake damaged concrete and masonry wall buildings: Basic Procedures Manual. Washington, D.C.: Federal Emergency Management Agency.

FEMA 356. 2000. Prestandard and commentary for the seismic rehabilitation of buildings. Washington, D.C.: Federal Emergency Management Agency.

Fleischman, R.B., and K.T. Farrow. 2001. Dynamic behavior of perimeter lateral-system structures with flexible diaphragms. Earthquake Engineering and Structural Dynamics 30 (5):745-63. WileyBlackwell. doi:10.1002/eqe.36.

Galasco A., S. Lagomarsino, A. Penna. 2002. Tremuri Program: Seismic Analyser of 3D Masonry Buildings. University of Genoa, Italy.

Galasco, A., S. Lagomarsino, and A. Penna. 2006. On the use of pushover analysis for existing masonry buildings. Proceedings of the First European Conference on Earthquake Engineering and Seismology, Geneva, Switzerland.

Gattesco, N., and L. Macorini. 2014. In-plane stiffening techniques with nail plates or CFRP strips for timber floors in historical masonry buildings. Construction and Building Materials 58:64-76. Elsevier. doi:10.1016/j.conbuildmat.2014.02.010.

Gattesco, N., I. Clemente, L. Macorini, and S. Noè. 2008. Experimental investigation on the behavior of spandrels in ancient masonry buildings. Proceedings of the $14^{\text {th }}$ World Conference on Earthquake Engineering, Beijing, China.

Giongo I., A. Wilson, D. Dizhur, H. Derakhshan, R. Tomasi, M. Griffith, P. Quenneville, and J. M. Ingham. 2014. Detailed seismic assessment and improvement procedure for vintage flexible timber diaphragms. Bulletin of New Zealand Society for Earthquake Engineering 47 (2):97118.

Giongo, I. 2013. Role of the timber diaphragms in the seismic response of unreinforced masonry (URM) buildings. PhD Thesis. University of Trento, Italy.

Giongo, I., G. Schiro, R. Tomasi, D. Dizhur, and J. Ingham. 2016. Seismic Assessment Procedures for Flexible Timber Diaphragms. Historical Earthquake-Resistant Timber Framing in the Mediterranean Area: 263-274. Springer. doi:10.1007/978-3-319-39492-3_22.

Gonzalez-Drigo, R., J. Avila, A. Barbat, L. Pujades, Y. Vargas, S. Lagomarsino, S. Cattari. 2015. Modernist URM buildings of Barcelona: Seismic vulnerability and risk assessment. International Journal of Architectural Heritage 9 (3):214-30. Taylor \& Francis.

Gonzalez-Drigo, R., J. Avila-Haro, L. G. Pujades, A. H. Barbat. 2017. Non-linear static procedures applied to high-rise residential URM buildings. Bulletin of Earthquake Engineering 15 (1):149-174. Springer Netherlands. doi:10.1007/s10518-016-9951-2.

Guerrini, G., F. Graziotti, A. Penna, and G. Magenes. 2017. Improved evaluation of inelastic displacement demands for short-period masonry structures. Earthquake Engineering \& Structural Dynamics 46 (9):1411-30. Wiley Online Library. doi:10.1002/eqe.2862.

Gubana, A. 2015. State-of-the-Art Report on high reversible timber to timber strengthening interventions on wooden floors. Construction and Building Materials 97: 25-33. Elsevier. doi:10.1016/j.conbuildmat.2015.06.035.

Halici, O.F., K. Ugurlu, C. Demir, M. Comert, and A. Ilki. 2018. Evaluation of diaphragm conditions in AAC floor structures with RC beams. Bulletin of Earthquake Engineering 16 (12):6131-162. Springer. doi:10.1007/s10518-018-0434-5.

Indirli, M., S. Kouris, L. A., Formisano, A., Borg, R. P., \& Mazzolani, F. M. 2013. Seismic Damage Assessment of Unreinforced Masonry Structures After The Abruzzo 2009 Earthquake: The Case Study of the Historical Centers of L'Aquila and Castelvecchio Subequo. International Journal of Architectural Heritage 7(5):536-578. doi:10.1080/15583058.2011.654050. 
Jain, S. K., and P. C. Jennings. 1985. Analytical models for low-rise buildings with flexible floor diaphragms. Earthquake Engineering and Structural Dynamics 13 (2):225-41. Wiley-Blackwell. doi:10.1002/eqe.4290130207.

Jiménez-Pacheco, J. 2016. Evaluación sísmica de edificios de mampostería no reforzada típicos de Barcelona: modelización y revisión de la aplicación del Método del Espectro de Capacidad. PhD Thesis. Politechnica University of Cataluña, Spain.

Ju, S. H., and M.C. Lin. 1999. Comparison of building analyses assuming rigid or flexible floors. Journal of Structural Engineering 125 (1):25-31. American Society of Civil Engineers (ASCE). doi:10.1061/(ASCE)0733-9445(1999)125:1(25).

Kallioras, S., G. Guerrini, U. Tomassetti, B. Marchesi, A. Penna, F. Graziotti, and G. Magenes. 2018. Experimental seismic performance of a full-scale unreinforced clay-masonry building with flexible timber diaphragms. Engineering Structures 161:231-49.

Kappos, A., G. Penelis, and C. Drakopoulos. 2002. Evaluation of simplified models for lateral load analysis of unreinforced masonry buildings. Journal of Structural Engineering 128 (7):890-97. doi: 10.1061/(asce)0733-9445(2002)128:7(890).

Kim, S., and D. White. 2004. MDOF response of low-rise buildings. ST-5 Project Final Report, Georgia Institute of Technology, Atlanta, USA.

Knox, C.L., and J. M. Ingham. 2012. Non-linear equivalent frame modelling: Assessment of a two storey perforated unreinforced masonry wall. New Zealand Society for Engineering Earthquake. Proceedings of the Annual Technical Conference, Christchurch, New Zealand.

Koliou, M., A. Filiatrault, D. J. Kelly, and J. Lawson. 2016. Buildings with Rigid Walls and Flexible Roof Diaphragms. I: Evaluation of Current U.S. Seismic Provisions. Journal of Structural Engineering 142 (3). American Society of Civil Engineers (ASCE). doi:10.1061/(asce)st.1943541x.0001438.

Kollerathu, J. A., and A. Menon. 2017. Role of diaphragm flexibility modelling in seismic analysis of existing masonry structures. Structures 11:22-39. Elsevier. doi:10.1016/j.istruc.2017.04.001.

Kouris, A., Borg, P., Indirli, M. 2010. The L’Aquila Earthquake, April 6th, 2009: a review of seismic damage mechanisms. In: Proceedings of COST Action C26 "Urban Habitat Constructions Under Catastrophic Events”, Naples, Italy

Kunnath, S.K., N. Panahshahi, and A. M. Reinhorn. 1991. Seismic response of RC buildings with inelastic floor diaphragms. Journal of Structural Engineering 117 (4):1218-37. American Society of Civil Engineers (ASCE). doi:10.1061/(ASCE)0733-9445(1991)117:4(1218).

Kyvelou, P., L. Gardner, and D. A. Nethercot. 2017. Testing and Analysis of Composite Cold-Formed Steel and Wood-Based Flooring Systems. Journal of Structural Engineering 143 (11): 04017146. American Society of Civil Engineers (ASCE). doi:10.1061/(asce)st.1943-541x.0001885.

Lagomarsino, S., A. Galasco, A. Penna, S. Cattari. 2008. Tremuri program: Seismic Analyses of 3D Masonry Buildings - User Guide. University of Genoa, Italy.

Lagomarsino, S., A. Penna, A. Galasco, S. Cattari. 2013. Tremuri program: An equivalent frame model for the non-linear seismic analysis of masonry buildings. Engineering Structures 56:1787-99. Elsevier. doi:10.1016/j.engstruct.2013.08.002.

Lagomarsino, S., and S. Cattari. 2015a. PERPETUATE: guidelines for seismic performance-based assessment of cultural heritage masonry structures. Bulletin of Earthquake Engineering 13 (1):13-47. Springer Netherlands. doi:10.1007/s10518-014-9674-1.

Lagomarsino, S., and S. Cattari. 2015b. Seismic performance of historical masonry structures through pushover and nonlinear dynamic analyses. In: Ansal A. (eds) Perspectives on European Earthquake 
Engineering and Seismology. Geotechnical, Geological and Earthquake Engineering 39:265-92. Springer, Cham. ISBN 978-3-319-16963-7.

Lagomarsino, S., D. Camilletti, S. Cattari, S. Marino. 2018. Seismic Assessment of Existing Irregular Masonry Buildings by Nonlinear Static and Dynamic Analyses. In: Pitilakis K. (eds) Recent Advances in Earthquake Engineering in Europe (ECEE 2018). Geotechnical, Geological and Earthquake Engineering 46: 123-51. Springer, Cham. ISBN 978-3-319-75741-4

Lagomarsino, S., S. Cattari, and C. Calderini. 2012. European Guidelines for the seismic preservation of cultural heritage assets. In: Deliverable D41, WP No8, PERPETUATE Project (FP7). European Research Project on the Seismic Protection of Cultural Heritage.

Lang, K. 2002. Seismic vulnerability of existing buildings. PhD Thesis. Institute of Structural Engineering and Swiss Federal Institute of Technology.

Lantada, N. 2007. Evaluación del Riesgo Sísmico Mediante Métodos Avanzados y Técnicas GIS. Aplicación a Barcelona. PhD Thesis. Politechnical University of Cataluña, Spain.

Liberatore, D., G. Spera, and D. Palermo. 2000. Seismic response of typical masonry buildings in the commune of Catania. Proceedings of the 12th World Conference on Earthquake Engineering, Auckland, New Zealand.

Lourenço, P. B., N. Mendes, L. F. Ramos, and D. V. Oliveira. 2011. Analysis of Masonry Structures Without Box Behavior. International Journal of Architectural Heritage 5 (4-5):369-82. Taylor \& Francis. doi:10.1080/15583058.2010.528824.

Magenes G., D. Bolognini, C. Braggio. 2000. Analisi dell' edificio in via Verdi, Progetto Catania: indagine sulla risposta sísmica di due edifici in muratura, Gruppo Nazionale per la Difesa dai Terremoti - GNDT, Rome, Italy. Available in: ftp://ftp.ingv.it/pro/gndt/Pubblicazione/

Magenes, G. 2000. A method for pushover analysis in seismic assessment of masonry buildings. Proceedings of the 12th World Conference on Earthquake Engineering, 1-8. Auckland, New Zealand.

Magenes, G., A. Penna, I. Senaldi, M. Rota, and A. Galasco. 2014. Shaking Table Test of a Strengthened Full-Scale Stone Masonry Building with Flexible Diaphragms. International Journal of Architectural Heritage 8 (3):349-75. Taylor \& Francis. doi:10.1080 / 15583058.2013.826299.

Magenes, G., and A. Penna. 2011. Seismic design and assessment of masonry buildings in Europe: recent research and code development issues. Proceedings of the 9th Australasian Masonry Conference, Queenstown, New Zealand.

Magenes, G., and G. M. Calvi. 1997. In plane seismic response of brick masonry walls. Earthquake Engineering \& Structural Dynamics 26 (11):1091-112. Wiley-Blackwell. doi: 10.1002/(SICI)10969845(199711)26:11<1091::AID-EQE693>3.0.CO;2-6.

Magenes, G., M. Remino, C. Manzini, P. Morandi, D. Bolognini. 2006. SAM II: Software for the Simplified Seismic Analysis of Masonry buildings. University of Pavia and EUCENTRE, Italy.

Mahdizadeh, A., J. Borzouie, and M. Raessi. 2012. New approach to seismic rehabilitation of masonry school buildings. Proceedings of the 15th World Conference on Earthquake Engineering, Lisbon, Portugal.

Maheri, M. 2004. Seismic evaluation and design of jack arch slabs. Proceedings of the 13th World Conference on Earthquake Engineering (13WCEE), Vancouver, Canada.

Mann, W., and H. Muller. 1982. Failure of shear-stressed masonry. An enlarged theory, tests and application to shear walls. Proceedings of the British Ceramic Society (30):223.

Marino, S., S. Cattari, and S. Lagomarsino. 2019. Are the nonlinear static procedures feasible for the seismic assessment of irregular existing masonry buildings?. Engineering Structures 200. doi.org/10.1016/j.engstruct.2019.109700 
Marques, R., and P. B. Lourenço. 2011. Possibilities and comparison of structural component models for the seismic assessment of modern unreinforced masonry buildings. Computers \& Structures 89:2079-91. Elsevier. doi:10.1016/j.compstruc.2011.05.021.

Marques, R., and P. B. Lourenço. 2014. Unreinforced and confined masonry buildings in seismic regions: Validation of macro-element models and cost analysis. Engineering Structures 64:52-67. Elsevier. doi:10.1016/j.engstruct.2014.01.014.

Mendes, N., P. B. Lourenço, and A. Campos-Costa. 2014. Shaking table testing of an existing masonry building: assessment and improvement of the seismic performance. Earthquake Engineering \& Structural Dynamics 43 (2):247-66. Wiley-Blackwell. doi:10.1002/eqe.2342.

Milutinovic, Z., G. Trendafiloski. 2003. WP4: Vulnerability of current buildings. RISK-UE Project handbook: An advanced approach to earthquake risk scenarios with applications to different European towns.

Moeini, M., and B. Rafezy. 2011. Investigation into the Floor Diaphragms Flexibility in Reinforced Concrete Structures and Code Provision. Global Journal of Research in Engineering 11 (1):25-35. Global Journals Inc.

Moon, S.K., and D. G. Lee. 1994. Effects of in plane floor slab flexibility on the seismic behavior of building structures. Engineering Structures 16 (2):129-44. Elsevier. doi:10.1016/01410296(94)90038-8.

Moreno-González, R., and J. M. Bairán. 2011. Análisis del comportamiento sísmico de los edificios de obra de fábrica, típicos del distrito Eixample de Barcelona. Informes de la Construcción 63 (524):2132. Instituto Técnico de la Construcción y del Cemento. doi:http://dx.doi.org/10.3989/ic.10.045.

Nakamura, Y., G. Magenes, H. Derakhshan, M. C. Griffith, and A. H. Sheikh. 2017a. Applicability of nonlinear static procedures for low-rise unreinforced masonry buildings with flexible diaphragms. Engineering Structures 137:1-18. Elsevier. doi:10.1016/j.engstruct.2017.01.049.

Nakamura, Y., H. Derakhshan, G. Magenes, and M. C. Griffith. 2017b. Influence of Diaphragm Flexibility on Seismic Response of Unreinforced Masonry Buildings. Journal of Earthquake Engineering 21 (6):935-60. Taylor \& Francis. doi:10.1080/13632469.2016.1190799.

NZSEE (2006) Assessment and improvement of the structural performance of buildings in Earthquakes. Recommendations of a NZSEE study group on earthquake risk buildings, 1-94. New Zealand Society for Earthquake Engineering (NZSEE) Inc, Wellington.

NZSEE (2017) The Seismic Assessment of Existing Buildings: Technical Guidelines for Engineering Assessments. New Zealand Society for Earthquake Engineering (NZSEE) Inc, Wellington.

Ortega, J., G. Vasconcelos, H. Rodrigues, M. Correia. 2018. Bulletin of Earthquake Engineering 16 (9):3871-904. Springer Netherlands. doi:10.1007/s10518-018-0318-8.

Pantò, B. 2003. Un nuovo macromodello per la valutazione della resistenza sismica di edifici in muratura. Master Thesis. Università Degli Studi Di Catania, Facoltà di Ingegneria, Dipartimento di ingegneria Civile ed Ambientale, Italy.

Pantò, B., F. Cannizaro, I. Caliò, P. Lourenço, P. 2017. Numerical and experimental validation of a 3D macro-model for the in-plane and out-of-plane behaviour of unreinforced masonry walls. International Journal of Architectural Heritage 11 (7):946-964.

Pantò, B., I. Caliò, and P. Lourenço. 2018. A 3D discrete macro-element for modelling the out-ofplane behaviour of infilled frame structures. Engineering Structures 175:371-385.

Paquette, J., and M. Bruneau. 2003. Pseudo-Dynamic Testing of Unreinforced Masonry Building with Flexible Diaphragm. Journal of Structural Engineering 129 (6):708-16. American Society of Civil Engineers (ASCE). doi:10.1061/(asce)0733-9445(2003)129:6(708). 
Paricio, A. 2008. Secrets d'un sistema constructiu: L'Eixample. Edicions UPC, Universitat Politecnica de Catalunya, Segona edició, Barcelona, Spain. ISBN 9788498802788.

Park, J., P. Towashiraporn, J. I. Craig, and B. J. Goodno. 2009. Seismic fragility analysis of low-rise unreinforced masonry structures. Engineering Structures 31 (1):125-37. Elsevier. doi:10.1016/j.engstruct.2008.07.021.

Pasticier, L., C. Amadio, and M. Fragiacomo. 2008. Non-linear seismic analysis and vulnerability evaluation of a masonry building by means of the SAP2000 v.10 Code. Earthquake Engineering \& Structural Dynamics 37 (3):467-485. Wiley-Blackwell. doi:10.1002/eqe.770.

Penna, A., I. Senaldi, A. Galasco, and G. Magenes. 2015. Numerical Simulation of Shaking Table Tests on Full-Scale Stone Masonry Buildings. International Journal of Architectural Heritage 10 (23):146-63. doi:10.1080/15583058.2015.1113338.

Penna, A., S. Lagomarsino, and A. Galasco. 2014. A nonlinear macroelement model for the seismic analysis of masonry buildings. Earthquake Engineering \& Structural Dynamics 43(2):159-79. WileyBlackwell. doi:10.1002/eqe.2335.

Peralta D.F., J.M. Bracci, and M.B.D. Hueste. 2000. Seismic performance of rehabilitated floor and roof diaphragms. Mid-America earthquake center project ST-8 final report. University of Illinois, EE. UU.

Petry, S., and K. Beyer. 2014. Influence of boundary conditions and size effect on the drift capacity of URM walls. Engineering Structures 65:76-88. Elsevier. doi:10.1016/j.engstruct.2014.01.048.

Pujades, L., A. Barbat, R. Gonzalez, J. Avila, S. Lagomarsino. 2012. Seismic performance of a block of buildings representative of the typical construction in the Eixample district in Barcelona (Spain). Bulletin of Earthquake Engineering 10 (1):331-49. Springer Netherlands. doi: 10.1007/s10518-0109207-5.

Quagliarini, E., G. Maracchini, and F. Clementi. 2017. Uses and limits of the Equivalent Frame Model on existing unreinforced masonry buildings for assessing their seismic risk: A review. Journal of Building Engineering 10:166-82. Elsevier. doi:10.1016/j.jobe.2017.03.004.

Raka, E., E. Spacone, V. Sepe, and G. Camata. 2015. Advanced frame element for seismic analysis of masonry structures: model formulation and validation. Earthquake Engineering \& Structural Dynamics 44 (14): 2489-506. Wiley-Blackwell. doi:10.1002/eqe.2594.

Rinaldin, G. 2011. Modellazione e analisi non lineare di structure in muratura e in legno. PhD Thesis. Università Degli Studi Di Trieste, Italy.

Rinaldin, G., C. Amadio, and L. Macorini. 2016. A macro-model with non-linear springs for seismic analysis of URM buildings. Earthquake Engineering \& Structural Dynamics 45 (14):2261-81. WileyBlackwell. doi:10.1002/eqe.2759.

Sadashiva, V., G. MacRae, B. Deam, M. Spooner. 2012. Quantifying the seismic response of structures with flexible diaphragms. Earthquake Engineering \& Structural Dynamics 41 (10):1365-89. Wiley-Blackwell. doi:10.1002/eqe.1187.

Saffarini, H. S., and M. M. Qudaimat. 1992. In-plane floor deformations in RC structures. Journal of Structural Engineering 118 (11):3089-102. American Society of Civil Engineers (ASCE). doi:10.1061/(asce)0733-9445(1992)118:11(3089).

Senaldi, I., G. Magenes, A. Penna, A. Galasco, and M. Rota. 2014. The Effect of Stiffened Floor and Roof Diaphragms on the Experimental Seismic Response of a Full-Scale Unreinforced Stone Masonry Building. Journal of Earthquake Engineering 18 (3):407-43. doi:10.1080/13632469.2013.876946.

Shakib, H., and A. R. Mirjalili, 2010. Experimental Investigation of the effect of transverse beams on the in-plane behavior of brick-flat-arch roofs. Journal of Seismology and Earthquake Engineering 12 (1-2):51-59. International Institute of Earthquake Engineering and Seismology (IIEES). 
Shakib, H., Mirjalili, A., Dardaei, S., and Mazroei, A. 2015. Experimental Investigation of the Seismic Performance of Retrofitted Masonry Flat Arch Diaphragms. Journal of Performance of Constructed Facilities 29 (4):1-11. American Society of Civil Engineers (ASCE). doi:10.1061/(asce)cf.19435509.0000611.

Srisangeerthanan, S., M. J. Hashemi, P. Rajeev, E. Gad, and S. Fernando. 2018. Numerical study on the effects of diaphragm stiffness and strength on the seismic response of multi-story modular buildings. Engineering Structures 163:25-37. Elsevier. doi:10.1016/j.engstruct.2018.02.048.

Tena-Colunga, A., and D.P. Abrams. 1996. Seismic behaviour of structures with flexible diaphragms. Journal of Structural Engineering 122 (4):439-45. American Society of Civil Engineers (ASCE). doi:10.1061/(ASCE)0733-9445(1996)122:4(439).

Tena-Colunga, A., K. L. Chinchilla-Portillo, and G. Juárez-Luna. 2015. Assessment of the diaphragm condition for floor systems used in urban buildings. Engineering Structures 93:70-84. Elsevier. doi:10.1016/j.engstruct.2015.03.025.

Tomazevic, M. 1999. Earthquake-resistance design of masonry buildings. London: Imperial College Press, (Series on innovation in structures and construction).

Valluzzi, M., E. Garbin, B. Dalla, C. Modena. 2010. In-plane strengthening of timber floors for the seismic improvement of masonry buildings. Proceedings of the 11th World Conference on Timber Engineering WCTE, Trentino, Italy.

Vila, J. 1989. La casa original del Ensanche de Barcelona: parámetros formales y métricos de la unidad residencial de la manzana Cerdá. PhD Thesis. Universitat Politècnica de Catalunya, Spain.

Wilson, A.W. 2012. Seismic Assessment of Timber Floor Diaphragms in Unreinforced Masonry Buildings. PhD Thesis. University of Auckland, New Zealand.

Wilson, A.W., P. J. H. Quenneville, and J. M. Ingham. 2014. In-Plane Orthotropic Behavior of Timber Floor Diaphragms in Unreinforced Masonry Buildings. Journal of Structural Engineering 140 (1):143. American Society of Civil Engineers (ASCE). doi:10.1061/(asce)st.1943-541x.0000819.

Zahrai, S. M., and L. Sarkissian. 2015. In-plane rigidity of laterally loaded composite floor systems, a finite element approach. Asian Journal of Civil Engineering 16 (2):161-81. Springer.

Zahrai, S.M., S. A. Zahraei, and M. R. Edalat. 2006. Evaluation of retrofitting methods for flexible floor slab. Proceedings of the First European Conference on Earthquake Engineering and Seismology, Geneva, Switzerland.

\section{LIST OF FIGURES}

Fig. 1 Prototype-Building: a) 3D View, b) Dimensions and scheme of the plan.

Fig. 2 Prototype-Building: a) Façade wall, b) Typical solid-hollow module in façade walls.

Fig. 3 Composite floor of steel beams and brick vaults adopted for the Prototype-Building.

Fig. 4 Proposed model for non-linear static pushover analysis of URM walls: a) Identification of piers and spandrels; b) Assembly of pier and spandrel macro-elements; c) Conformation of the generic macro-element.

Fig. 5 a) Configuration of the spring element of Ruaumoko, b) Characterization of the spring element of Ruaumoko.

Fig. 6 Graphic scheme of the assembly of the stiffness sub-matrices $\mathrm{K}_{\mathrm{s}}$. 
Fig. 7 Corrective factor of shear stress as a function of the slenderness.

Fig. 8 Force-displacement relationships assumed for the piers: a) shear, b) bending moment.

Fig. 9 Force-displacement relationships assumed for the spandrels: a) shear, b) bending moment.

Fig. 10 Pavia door-wall: a) dimensions; b) identification of piers and spandrels; c) weights and vertical loads.

Fig. 11 Pavia window-wall: a) dimensions; b) identification of piers and spandrels; c) weights and vertical loads.

Fig. 12 Catania project - Wall D: a) dimensions; b) identification of piers and spandrels; c) weights and vertical loads.

Fig. 13 Paquette and Bruneau, West Wall: a) dimensions; b) identification of piers and spandrels; c) weights and vertical loads.

Fig. 14 Pushover curves of the Pavia walls obtained for the three considered BCPs versus experimental curves: a) door-wall, b) window-wall.

Fig. 15 Pushover curves of Wall D - Catania project obtained for the three considered BCPs versus numerical simulations: a) quasi-triangular lateral load; b) uniform lateral load.

Fig. 16 Pushover curves of West-Wall tested by Paquette and Bruneau (2003) obtained for the three considered BCPs: a) fully developed; b) amplified in the initial range of displacement.

Fig. 17 Elastic stiffness vs. BCPs ( $\left.\psi^{\prime}\right)$ : a) total set of ordered pairs, b) subset of ordered pairs in the range of elastic stiffnesses.

Fig. 18 a) Base shear capacity vs. BCPs ( $\left.\psi^{\prime}\right)$, b) Lateral drift vs. BCPs ( $\left.\psi^{\prime}\right)$.

Fig. 19 Final state of force-displacement relationships (FDRs) more developed: a) Pavia's door-wall, b) Wall-D, Catania Project.

Fig. 20 Deformed shape of flexible diaphragm (without torsion): shear and bending deformation components

Fig. 21 a) Ideal plate under simple shear; b) basic macro-element floor diaphragm to simulate the behavior of the ideal plate (for lateral load in the indicated direction).

Fig. 22 a) Assembly of the macro-element floor diaphragm on the system of equivalent frames, b) 3Dmodel implemented on Pavia prototype-building.

Fig. 23 a) Pavia prototype-building, b) Transfer of vertical loads from unidirectional floor system to the piers.

Fig. 24 Display of the model of the Pavia prototype-building: a) Ruaumoko model and global axes; b) Tremuri model and displacement control nodes.

Fig. 25 Pushover curves obtained with Ruaumoko on Pavia prototype-building under two BCPs (cantilever and intermediate) versus pushover curves obtained with Tremuri: a) with displacement control node on the door-wall, b) with displacement control node on the window-wall.

Fig. 26 Adaptation of equivalent frame to the prototype building: a) façade wall, b) interior wall. 
Fig. 27 a) Consideration of segmentation and adjacency on floor diaphragm macro-elements when assemble them on two-span building, b) Detail of the characterization by means of shear stiffnesses of the selected floor diaphragm macro-element.

Fig. 28 Contribution of tributary masses to nodal masses: a) from walls, b) from floor diaphragms.

Fig. 29 Comparison between the pushover curves of the prototype-building obtained with Ruaumoko (considering three boundary conditions of the piers) and those obtained with Tremuri: a) lateral load parallel to transverse direction-X, b) lateral load parallel to longitudinal direction$\mathrm{Z}$.

Fig. 30 Stiffening interventions adopted for SBBV-floor: a) floor stiffened with diagonal bracing, b) floor stiffened with a concrete topping (taken from Maheri 2004).

Fig. 31 Pushover curves of the PB with SBBV-floor: unstiffened case, stiffened variants and variants with very flexible floor and fully rigid floor. Lateral load parallel to the transverse direction-X.

Fig. 32 Pushover curves of the PB with SBBV-floor: unstiffened case (PB-US), stiffened variant (PBS2) and variant with fully rigid floor (PB-RF). Lateral load parallel to the transverse direction $(\mathrm{X})$ and to the longitudinal direction $(\mathrm{Z})$.

Fig. 33 Deformed shape of the floors under lateral load parallel to transverse direction (X) just before of the drop of strength: a) PB-US case, b) PB-S2 variant, c) PB-RF variant.

Fig. 34 Timber floor variants adopted: a) Unstiffened timber floor and load components, b) Timber floor stiffened with double orthogonal sheathing, c) Timber floor with diagonal strips of CFRP (taken from Gattesco and Macorini, 2014).

Fig. 35 a) In-plane deformation of a single straight sheathing timber floor, b) Distribution of forces. Contributions of deformability: c) rigid rotation of the board due to nails slip, d) board shear deformation, e) board flexural deformation.

Fig. 36 Pushover curves of the PB with timber floor versus pushover curves of the PB with SBBVfloor: unstiffened variants, stiffened variants (including variant with fully rigid floor). Lateral load parallel to the transverse direction $(\mathrm{X})$.

Fig. 37 Profiles of lateral displacement of two walls selected on three PB variants with timber floor (unstiffened: PB-TF-US, stiffened: PB-TF-S1 and fully rigid: PB-RF) established in an instant of the pushover analysis just before the sustained strength degradation: a) control points on the pushover curves of outer wall; b) control points on the pushover curves of inner wall; c) Profiles of lateral displacement of outer wall on three variants of the PB with timber floor; d) Profiles of lateral displacement of inner wall on four variants of the PB with timber floor and PB variant with SBBV-floor.

\section{LIST OF TABLES}

Table 1 Wall thicknesses of the Prototype-Building.

Table 2 Heights of doors and windows in Prototype-Building.

Table 3 Mechanical properties adopted for unreinforced masonry of the Prototype-Building.

Table 4 Load components of SBBV-floor. 
Table 5 Failure modes and strength capacities assumed for piers and spandrels.

Table 6 Mechanical properties of the unreinforced masonry of the walls studied.

Table 7 Basic references and features of the studies considered.

Table 8 Results of test of Shakib and Mirjalili (2010).

Table 9 Basic modal properties obtained with the Proposed Model (PM) and with Tremuri.

Table 10 Stiffening factors for stiffened variants PB-S1 and PB-S2.

Table 11 Modal parameters on PB variant with fully rigid floor.

Table 12 Modal parameters on unstiffened case (PB-US) and stiffened variant (PB-S2).

Table 13 Characteristics of the buildings analyzed and the types of analyses in studies considered.

Table 14 Importance of the variations provoked by the stiffening of the floor system on the three seismic responses studied. 